\title{
Not in My Community: Social Pressure and the Geography of Dismissals
}

\author{
Andrea Bassanini, OECD (Organization for Economic Coopera- \\ tion and Development) and IZA (Institute for the Study of Labour)
}
Giorgio Brunello, University of Padova, CESifo (Center for Eco- nomic Studies, Ifo Institute, and Munich Society for the Promotion of Economic Research), IZA, and ROA (Research Centre for Education and the Labour Market)
Eve Caroli, PSL (Paris Sciences et Lettres), Université Paris-Dauphine, LEDa (Laboratoire d'Economie de Dauphine), Paris School of Economics, and IZA

\begin{abstract}
We investigate the impact of local social pressure on firms' firing decisions. Using linked employer-employee data, we show that secondary establishments located further away from headquarters have higher dismissal rates than those located closer. The effect of distance on dismissals is stronger, the greater the visibility of the firm in the local community of its headquarters and the larger the degree of selfishness of that community. We show that these findings can be explained by the social pressure exerted by the communities where firms' headquarters are located, which induces CEOs to refrain from dismissing at short distance from their headquarters.
\end{abstract}

The views expressed here are those of the authors and cannot be attributed to the OECD or its member countries. We are indebted to IFOP (Institut Français d'Opinion Publique) for generously sharing their data on Catholicism in France with us. We are grateful to Philippe Askenazy, Erich Battistin, Marco Bertoni, Vincent Bignon, Matthias Bürker, Christiane Caroli, Matthieu Crozet, Pierre-Philippe Combes, Salvo Di Falco, 


\section{Introduction}

There is growing evidence in the literature that firms are sensitive to social pressure and that this affects their decisions. Good examples of this can be found in the area of corporate social responsibility (see, e.g., Schmitz and Schrader 2015). It has been shown that firms accommodate social pressure in order to maximize their market value, since socially responsible actions increase customers' propensity to buy their goods and services (see Luo and Bhattacharya 2006; Baron 2011). Moreover, some scholars argue that if firm's stakeholders are philanthropic, they may ask firms to do good on their behalf. More specifically, if stakeholders want firms to behave as good corporate citizens, "delegated philanthropy" may induce firms to refrain from polluting, engage in fair-trade activities, and so forth. In this case, social pressure affects firms' decisions even if it has no direct impact on their profits (see Benabou and Tirole 2010).

Social pressure also arises at the local level when communities try to protect themselves from projects that would generate a disproportionate cost for them. One example is the resistance of local communities against the implantation of polluting infrastructure in their district-the so-called NIMBY (Not in My Backyard) syndrome (e.g., Frey, Oberholzer-Gee, and Eichenberger 1996). Beyond polluting projects, any action that may generate damages to the local community is likely to give rise to social pressure opposing it.

Massive dismissals have long been considered as a major threat to local communities, as shown by their prominence in popular media (see, e.g., Michael Moore's 1989 film Roger and Me, focusing almost entirely on the consequences of the massive downsizing carried out by General Motors in

Gilles Duranton, Margherita Fort, Alex Hijzen, Miren Lafourcade, Alexander Lembcke, Carlo Menon, Michele Pellizzari, Enrico Rettore, Frédéric Robert-Nicoud, Lorenzo Rocco, Sébastien Roux, François Ryckx, and Maurizio Zanardi, as well as participants to seminars at the University of Geneva, GATE (Groupe d'Analyse et de Théorie Economique)-Lyon II, EconomiX-Paris Ouest University, ADIS (Analyse Sociale des Dynamiques Industrielles), and CES-ENS-Cachan (Centre d'Economie de la Sorbonne-Ecole Normale Supérieure de Cachan Hotelling seminar), ZEW (Centre for European Economic Research) Manheim, the OECD, LEDa-Université Paris Dauphine, and Lancaster University Management School, and at the Conference on Firm-Level Analysis of Labour Issues, Louvain-la-Neuve, May 2014, the 5th IZA Conference on Entrepreneurship, Potsdam, July 2014, and the ESSLE (European Summer Symposium in Labour Economics) Symposium, Buch am Ammersee, September 2014, who provided useful comments and suggestions. We also thank Matteo Bassanini for excellent research assistance. All remaining errors are ours. Eve Caroli is grateful to LABEX OSE (Laboratoire d'Excellence Ouvrir la Science Economique) and CEPREMAP (Centre pour la Recherche Economique et ses Applications) for financial support. Contact the corresponding author, Eve Caroli, at eve.caroli@dau phine.fr. Information concerning access to the data used in this article is available as supplementary material online. 
Flint, Michigan). More generally, avoiding the social cost of dismissals is typically acknowledged as one of the key reasons justifying firing regulations (e.g., Cahuc and Zylberberg 2008; Jung and Kuester 2015). This suggests that local communities are likely to put firms under strong pressure in order to limit the number of dismissals in their surroundings as much as possible.

In this paper, we show that dismissal rates increase with the distance of the plant to the firm's headquarters and that a key factor explaining this fact is local social pressure at headquarters. Following Akerlof (1980), we consider that CEOs care about their reputation in the community where they work, and most often live, ${ }^{1}$ and hence have the most frequent interactions. ${ }^{2}$ In this framework, when CEOs dismiss local employees, they are perceived as causing damage to their community, which triggers social sanctions in the form of a reduction in reputation. ${ }^{3}$ Social pressure, that is, the threat of these sanctions, is therefore likely to induce CEOs to refrain from firing workers close to headquarters, that is, in their local community. As emphasized by Bill Dugovich, a spokesman for the Society of Professional Engineering Employees in Aerospace, at the time Boeing moved its headquarters from Seattle to Chicago, "It really makes it easier for them to make those difficult public statements, like when you move wing production to Japan or move workers from Renton to Everett . . when you're sitting . . in Chicago.”4

We present a simple theoretical model with employment adjustment costs in which the threat of social sanctions is perceived by the CEO as an additional dismissal cost. Since CEOs are sensitive to potential social sanctions arising from their own community and since this community opposes more strongly local dismissals, perceived adjustment costs are higher for plants located closer to the headquarters. As is standard in labor demand models, dismissals are decreasing with adjustment costs and hence increasing with the distance of the plant to the headquarters. We also derive two other predictions that allow us to distinguish empirically our social pressure story from other potential explanations of a positive relationship between distance and dismissals: the distance-dismissal relationship should be steeper (i) the greater is the visibility of the firm in the community of its headquarters

${ }^{1}$ Data from the European Labour Force Survey indicate that in France 95\% of the CEOs work and live in the same region.

${ }^{2}$ As Akerlof put it, "Anthropological studies abound with evidence that persons care deeply about their reputations in their communities” $(1980,753)$.

${ }^{3}$ For example, such social sanctions may take the form of a strong disapproval of the CEO's behavior which makes her or her family feel embarrassed in social encounters.

${ }^{4}$ See Luke Timmerman, “Angry Unions Feel Betrayed, Fear for Future of Local Jobs," Seattle Times, March 22, 2001. Two weeks after moving its headquarters to Chicago, Boeing announced a plan to lay off almost 30,000 employees in the Seattle area (see, e.g., "First Boeing Employee Layoffs Set to Take Effect Dec. 14," Daily Journal of Commerce, September 27, 2001). 
and (ii) the more selfish is the local community at headquarters. The former prediction is consistent with the idea that the incentive that a firm has to engage in a behavior demanded by stakeholders increases with the firm's visibility with respect to these stakeholders (Benabou and Tirole 2010). The latter prediction is consistent with the idea that when "public spirit" is lower, communities care essentially about themselves and are more prone to shift the burden of painful adjustments onto others (Frey et al. 1996).

Our empirical analysis is based on French data. Looking at France to study the geographical dispersion of dismissals is interesting because the threshold number of dismissals beyond which (more expensive) collective dismissal procedures apply is defined at the firm level. This implies that, since dismissals in a plant affect the cost of dismissals in other plants of the same firm, the decision to dismiss has to be handled at the firm level. By contrast, in many other countries (e.g., the United States and the United Kingdom), the collective dismissal threshold is set at the establishment level, so individual plants may take dismissal decisions in a more independent way. We match two large plant-level administrative data sets that also contain information on workers: (i) the Déclarations Annuelles des Données Sociales (DADS), which contains complete social security records, including the geographical location of the plant and the firm's headquarters, and covers all plants and firms in the nonagricultural business sector, and (ii) the Déclarations des Mouvements de Main d'Oeuvre (DMMO-EMMO), which contains quarterly worker flows for all plants with more than 50 workers and a $25 \%$ random sample of those plants with between 10 and 50 workers. By matching these data sets, we obtain information on the geographical dispersion of worker flows for over 5,000 multi-establishment firms and over 29,000 plants for the period 2003-7.

Using these data, we investigate the relationship between distance to headquarters and dismissals and the potential role of social pressure in shaping it. We first show that within the same firm, secondary establishments located further away from the headquarters have higher dismissal rates than establishments located closer to them. When conducting our analysis, we take into account the potential endogeneity of distance to headquarters. More specifically, we instrument actual distance with potential distance, defined as the distance at which the establishment would have been from the headquarters had its location been chosen only to maximize the market potential of the firm (measuring the capacity of the firm to serve large local markets while minimizing transport costs). We discuss in detail why potential distance is likely to be a valid instrument in the current setup. As a second step, we test the additional predictions of our model and hence provide evidence that the distance-dismissal relationship is at least partly due to social pressure in the local community where the firms' headquarters are located. We first show that the positive effect of distance on dismissals increases with the firm's visibility at headquarters. More precisely, the larger is the 
weight of the firm in the total employment of its headquarters' local labor market, the stronger is the positive effect of distance on dismissals. We then show that the effect of distance is greater the more selfish the local community is where the headquarters are located. We measure selfishness as the inverse of local generosity and capture the latter with the share of charitable giving in local gross domestic product and, as a robustness check, as the difference in turnout rates between national and local elections. In light of our model, we interpret these results as providing evidence that managerial decisions regarding dismissals are affected by social pressure exerted by the CEO's local community.

We are aware of only three other papers pointing to a relationship between distance to headquarters and employment downsizing in secondary plants (Landier, Nair, and Wulf 2009; Giroud 2013; Kalnins and Lafontaine 2013), all of which use US data. These papers suggest that the positive relation between distance and dismissals is largely due to information asymmetries and monitoring costs. Landier et al. (2009) also point out that social factors are likely to be important, in particular altruistic attitudes of managers - either toward firm employees or the local community - and social pressure..$^{5}$ Although we do not exclude that other explanations may play a role in explaining the relationship between distance and dismissals, we show that only social pressure arising from the local community of the headquarters can account for the significant interactions between distance and visibility, on the one hand, and distance and generosity, on the other hand. We conclude that local social pressure at headquarters is the only possible explanation that can account for all our empirical findings, thereby showing that it is a key factor shaping the geography of dismissals.

Our paper also relates to the literature on weak corporate governance and entrenchment. As shown in the literature (e.g., Bertrand and Mullainathan 2003; Giroud and Mueller 2010; Bach and Serrano-Velarde 2015), entrenched managers look for a "quiet life" and therefore tend to buy peace with their workers by paying them higher than profit-maximizing wages and/or offering them greater job security. Cronqvist et al. (2009) show that this effect is stronger for workers who are closer to the CEO, either within the organizational hierarchy or because they work in the same municipality. This suggests that CEOs are sensitive to the social pressure arising from within the firm. Our paper shows that they are also sensitive to local social pressure arising from outside the firm.

Our paper also speaks to the literature on image-motivated altruism and social pressure. Research in this area shows that individuals want to be liked

${ }^{5}$ D'Aurizio and Romano (2013) also provide evidence that, during the Great Recession, Italian family firms have faced increasing social pressure to act as social buffers: confronted with a large negative aggregate shock, they have expanded employment in the region of their headquarters, while reducing it in other regions. 
and respected by others and that they seek to gain social approval of their behavior (see, e.g., Andreoni and Bernheim 2009). Of course, the value of image depends on visibility. It has been shown that individuals are much more altruistic when their actions are made public rather than remain private information and that the degree of altruism increases with visibility (Freeman 1997; Andreoni and Petrie 2004; Ariely, Bracha, and Meier 2009; Soetevent 2011; Filiz-Ozbay and Ozbay 2014). Apparently altruistic behaviors are often the result of selfish individuals trying to escape the threat of social sanctions (Della Vigna, List, and Malmendier 2012). This suggests that altruism (or apparent altruism) is, at least partly, image motivated and that individuals are sensitive to the social pressure arising from their immediate social environment. When visibility is very high, the threat of social sanctions may even lead agents to make decisions that breach professional ethics. For instance, Garicano, Palacios-Huerta, and Prendergast (2005) indeed show that soccer referees internalize the preferences of the crowd attending the matches in their decisions by systematically favoring the home team. ${ }^{6}$ In this paper, we show that social pressure arising from the community also affects human resource management practices when the firm is highly visible in its community.

The layout of the rest of the paper is as follows. Section II presents a simple model of social pressure and dismissals. Section III describes the data and presents summary statistics. In Section IV, we explain our empirical strategy. Section $\mathrm{V}$ reports the empirical results. Alternative explanations are discussed in Section VI. Section VII concludes.

\section{A Simple Model of Social Pressure and Dismissals}

In this section, we sketch a highly stylized model of employment decisions under social pressure and derive three testable predictions that we use to empirically disentangle the impact of social pressure from that of other potential mechanisms explaining the relationship between distance to headquarters and dismissals. We assume a continuum of identical firms between 0 and 1 .

Each firm is composed of two production plants and the headquarters. Near each plant and the headquarters lives a community. No production occurs at the headquarters. We index by 1 the plant that is the closest to the headquarters and by 2 the plant that is further away. ${ }^{7}$ Employment decisions are taken by the $\mathrm{CEO},{ }^{8}$ who works in the municipality where the

${ }^{6}$ Social pressure has also been shown to play a role in reducing the absenteeism of public sector employees (De Paola, Scoppa, and Pupo 2014).

7 We do not model here why a firm has more than one plant and why plants are located at different distances from headquarters.

${ }^{8}$ Our assumption is that employment decisions are taken centrally at headquarters. For the sake of simplicity, we represent these decisions as taken by the CEO even if, in practice, they may also be taken by other top executives. 
headquarters are located. Following Akerlof (1980), we assume that the $\mathrm{CEO}$ cares about profits and her reputation. A community can sanction the $\mathrm{CEO}$ when he/she is perceived as harming it. Sanctions take the form of a reduction in the CEOs' reputation within the community. The CEO maximizes the present discounted value of his/her utility, which is affected positively by profits and negatively by social sanctions. The instantaneous utility $U$ of the CEO of firm $F$ at time $t$ is given by

$$
U_{F t}=\pi_{F t}-\mathrm{SS}_{F t} \text {, }
$$

where $\pi$ stands for profits and SS for social sanctions. Communities care about dismissals and therefore can sanction the CEOs of firms that fire employees. In principle, CEOs could be sensitive to the threat of social sanctions - that is, social pressure - exerted by any community, both those of the plants and of the headquarters. However, it is quite likely that they are more sensitive to their reputation in the community where they work and most often live. For the sake of simplicity, we assume that CEOs are only sensitive to their reputation in their own community, that is, at headquarters, so that their behavior is not influenced by social pressure at plants. When presenting the results, we will provide evidence that this is actually the case in our data (see Sec. V.B.).

Modeling social sanctions as a linear function of dismissals, the CEO's instantaneous utility may be rewritten as

$$
U_{F t}=\pi_{F t}-b_{1} D_{1 F t}-b_{2} D_{2 F t},
$$

where $D$ denotes dismissals and $b_{i}>0$. We assume that the local community particularly dislikes dismissals when they take place at a short distance, since this increases the risk that local people are affected. In addition, the more selfish the local community is, the less it cares about dismissals affecting other communities. This implies that $b_{1}>b_{2}$ and that the gap between $b_{1}$ and $b_{2}$ is larger the greater the degree of selfishness of the local community where the firm's headquarters are located.

Both plants produce final output. For simplicity, their production functions are assumed to be identical and independent from one another. ${ }^{9}$ They can be written as $f\left(\theta_{i t}, N_{i t}\right)$, where $i=1,2$ indexes plants, $N$ denotes employment, ${ }^{10}$ and $\theta$ is a productivity shock-with $f$ increasing in $\theta$ - taking the

${ }^{9}$ Giroud and Mueller (2015) show that idiosyncratic shocks affecting one plant have, on average, no impact on the level of employment of other plants in the same firm, except if the latter is financially constrained. This suggests that our assumption of separability is not inconsistent with empirical evidence. In the case of firm-level shocks, it can be easily shown that our results also hold in the absence of separability. Proof is available from the authors upon request.

10 Index $F$ is omitted hereafter to simplify the notation. 
form of a Poisson process with two states: $\operatorname{good}(G)$ and bad $(B)$, so that $\theta_{G}>$ $\theta_{B}$. Shocks are identically distributed across plants and firms. They are also independent across firms, although they may be correlated across plants of the same firm. Let the instantaneous probability of transition between $G$ and $B$ be denoted by $\lambda_{G}$ and the probability of transition between $B$ and $G$ be denoted by $\lambda_{B}$. We also assume that $f$ is continuous and three times differentiable, with $f_{\mathrm{N}}>0, f_{N N}<0$, and $f_{\mathrm{NNN}} \geq 0$, where $f_{\mathrm{N}}, f_{\mathrm{NN}}$, and $f_{\mathrm{NNN}}$ denote the first, second, and third derivatives with respect to $N$, respectively.

Plants are wage-takers and firms are price-takers, with the price of output normalized to 1 . Therefore, wages and prices do not vary according to whether plants are in a good or bad state. Employment increases with hirings and decreases with dismissals. Dismissals occur in the presence of negative shocks - productivity shifts from the good state to the bad stateand hirings take place with positive shocks - or shifts from the bad state to the good state. We rule out voluntary quits and churning for the sake of simplicity. Therefore, dismissals are equal to the absolute value of employment changes when the latter are negative, and zero otherwise, and hirings are equal to the absolute value of employment changes when positive, and zero otherwise. Both hirings and dismissals are costly. Adjustment costs are assumed to be linear in employment changes and identical across plants. In particular, hiring costs are given by $\mathrm{HC}_{i}=c_{b} H_{i}$ - with $H$ standing for hirings - and dismissal costs are given by $\mathrm{DC}_{i}=c_{d} D_{i}$.

Following Cahuc and Zylberberg (2004), we restrict our attention to stationary employment levels. Given these assumptions, we can rewrite equation (1) as follows:

$$
U_{t}=\sum_{i=1}^{2} f\left(\theta_{i t}, N_{i t}\right)-\sum_{i=1}^{2} w_{t} N_{i t}-\sum_{i=1}^{2} c_{h} H_{i t}-\sum_{i=1}^{2}\left(c_{d}+b_{i}\right) D_{i t},
$$

where $w_{t}$ denotes the wage rate. By construction, this utility function is separable across plants. Therefore, the CEO's intertemporal maximization problem comes down to maximizing separately the contribution of each plant to the present discounted value of his/her utility. This corresponds, for each plant, to a standard model with adjustment costs, the solution of which is well known (see, e.g., Cahuc and Zylberberg 2004): optimal employment fluctuates between two values depending on whether the plant is in a good state or a bad state:

$$
\begin{gathered}
f_{\mathrm{N}}\left(\theta_{G}, N_{i}^{G}\right)=w+\lambda_{G}\left(c_{d}+b_{i}\right)+\left(r+\lambda_{G}\right) c_{b} \text { if } \theta_{i t}=\theta_{G}, \\
f_{\mathrm{N}}\left(\theta_{B}, N_{i}^{B}\right)=w-\lambda_{B} c_{b}-\left(r+\lambda_{B}\right)\left(c_{d}+b_{i}\right) \text { if } \theta_{i t}=\theta_{B},
\end{gathered}
$$

where $r$ is the discount rate of the CEO, and the values $N^{G}$ and $N^{B}$ correspond to the levels of labor demand in the good and bad states, respectively, 
under the assumption that the difference between $\theta_{G}$ and $\theta_{B}$ is sufficiently large so that $N^{G}>N^{B}{ }^{11}$

Defining optimal dismissals as $D_{i}^{*}\left(b_{i}\right)=N_{i}^{G}-N_{i}^{B}$, exploiting the properties of the derivative of inverse functions, and taking into account that $f_{\mathrm{NN}}<0$, we have:

$$
\frac{\partial D_{i}^{*}}{\partial b_{i}}=\frac{\partial N_{i}^{G}}{\partial b_{i}}-\frac{\partial N_{i}^{B}}{\partial b_{i}}=\frac{\lambda_{G}}{f_{\mathrm{NN}}\left(\theta_{G}, N_{i}^{G}\right)}+\frac{r+\lambda_{B}}{f_{\mathrm{NN}}\left(\theta_{B}, N_{i}^{B}\right)}<0 .
$$

Therefore, $b_{1}>b_{2}$ implies that the plant that is further away from the headquarters dismisses more workers when hit by a negative shock than does the plant that is closer; that is, $D_{1}^{*}\left(b_{1}\right)<D_{2}^{*}\left(b_{2}\right)$. This is shown graphically in figure 1. Adjustment costs generate a positive (negative) wedge between labor productivity and the market wage in the good (bad) state (see eqq. [2] and [3]). Since this wedge is greater in plants that are closer to headquarters, in order to minimize potential social sanctions, CEOs optimally choose smaller employment adjustments there.

Assuming that the economy is in a stationary equilibrium with a proportion $\rho$ of plants in a good state, having a continuum of identical firms that are subject to independent and identically distributed (i.i.d.) shocks implies that at each point in time there are $\rho \lambda_{G}$ plants of both types (1 and 2) whose state shifts from good to bad, thereby giving rise to dismissals. Aggregating across firms and using the law of large numbers, we obtain for each type of plant,

$$
E\left(D_{i F t}\right)=\int D_{i F t} d F=\rho \lambda_{G} D_{i}^{*}\left(b_{i}\right),
$$

where $E$ is the expectation operator. In other words, at any point in time, aggregate dismissals in plants of type $i$ are proportional to $D_{i}^{*}$ and therefore lower in plants located closer to headquarters than in plants located further away.

This model may be easily generalized to an arbitrary number of plants, thereby generating an inverse relation between distance to headquarters and dismissals, by assuming that $b_{i}$ decreases with the distance of plant $i$ to the firm's headquarters. This assumption captures the fact that the local community of the headquarters is likely to care more about communities located closer-and with which its members have frequent interactionsthan about communities located further away. ${ }^{12}$

${ }^{11}$ If this assumption does not hold, employment never changes, so hirings and dismissals are always equal to zero.

12 The Contact entre les personnes (Contact between people) survey carried out by the French Statistical Institute (INSEE) in 1983 provides evidence that the intensity of social relations decreases with the distance between individuals. Using these data, one can compute the frequency of encounters of an individual with his/her 


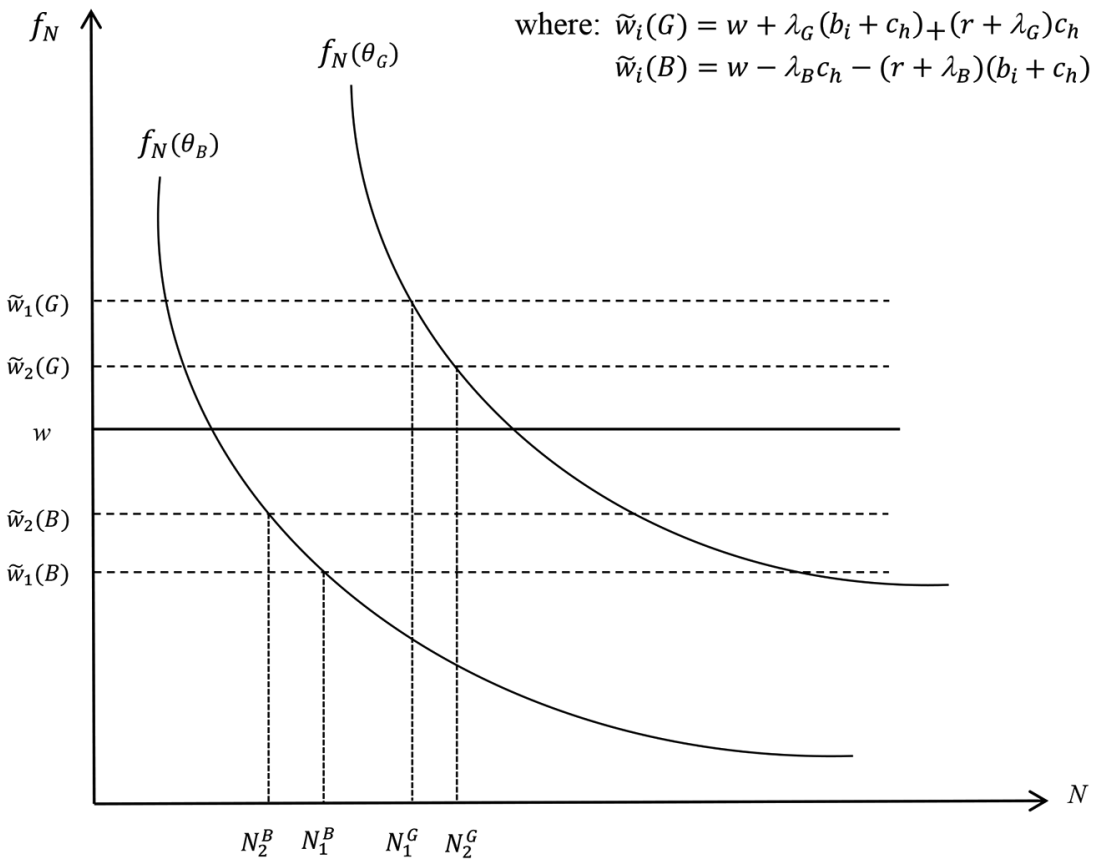

FIG. 1.-Marginal output, employment and wages (including the correction for the wedge induced by adjustment costs) in close and distant plants, where 1 and 2 denote close and distant plants, respectively, and $G$ and $B$ denote the good state and the bad state, respectively. Since the adjustment-cost wedge is greater in plants that are closer to the headquarters, in order to minimize potential social sanctions, CEOs optimally choose smaller employment adjustments there.

Benabou and Tirole (2010) argue that the incentive for a firm to engage in a behavior demanded by stakeholders increases with its visibility with respect to them. We therefore expect social sanctions to be greater, and hence social pressure to be more effective, the greater the visibility of the firm in the community of its headquarters. This implies that $b_{i}$ can be rewritten as

$$
b_{i}=\alpha \gamma_{i}
$$

parents, in-laws, children, and friends. The data set also provides information on the distance at which these relatives and friends live. When using the frequency of encounters as a proxy of the intensity of social relations, the latter turns out to be negatively correlated with the geographical distance between individuals: for distances higher than 5 kilometers, involving 17,797 couples of individuals, we find that the coefficient of correlation between distance and the frequency of encounters is -0.05 , which is significant at the $1 \%$ level. 
with $\alpha$ increasing in the firm's visibility at the headquarters and $\gamma_{i}$ representing the sensitivity of social sanctions to dismissals for a given level of visibility. Our above-mentioned assumption that local communities particularly dislike dismissals when they take place at short distance translates into $\gamma_{1}>\gamma_{2}$, with the gap between $\gamma_{1}$ and $\gamma_{2}$ being larger the greater the degree of selfishness of the local community where the headquarters are located. Let us therefore write $\gamma_{2}=\gamma_{1} / \beta$, where $\beta>1$ is a measure of the degree of selfishness of the local community of the headquarters.

We show in Appendix Section A1 that if the degree of selfishness is high enough, $\partial\left(D_{2}^{*}-D_{1}^{*}\right) / \partial \alpha>0$. In other words, if the community of the headquarters is sufficiently selfish, the more visible the firm is, the stronger the effect of distance on dismissals. It also follows from equation (4) that $\partial\left(D_{2}^{*}-D_{1}^{*}\right) / \partial \beta>0$; that is, an increase in the degree of selfishness at headquarters also increases the effect of distance on dismissals. Finally, as shown in Appendix Section A2, if the degree of selfishness is large enough, $\partial^{2}\left(D_{2}^{*}-D_{1}^{*}\right) / \partial \alpha \partial \beta>0$. In other words, if the community where the headquarters are located is sufficiently selfish, the effect of visibility on the steepness of the relationship between distance and dismissals increases with the degree of selfishness.

To sum up, our model shows that the threat of social sanctions by the local community, that is, local social pressure, may generate a positive relationship between distance to headquarters and dismissals. The model also provides three additional testable predictions. For a sufficiently high degree of selfishness, the effect of distance on dismissals (i) increases with the firm's visibility in the community of its headquarters, (ii) increases with the degree of selfishness of this community, and (iii) is magnified wherever high visibility combines with a strong degree of selfishness in the community of the headquarters. In the remainder of the paper, we test these predictions and use them to disentangle the role played by local social pressure at headquarters from other explanations provided in the literature to account for the observed geographical pattern of dismissals.

\section{The Data}

Since we need to combine information on dismissals, distance of secondary establishments to headquarters, local generosity, and a number of establishments', as well as local areas' characteristics, our data come from different sources.

The first data source we use contains social security records - the DADS, Déclarations Annuelles de Données Sociales. It covers the universe of establishments and firms in all sectors except agriculture, part of the foodprocessing industry, and rural financial institutions (e.g., Crédit Agricole). We have access to the DADS since 1997. This source contains, on average, 1,350,739 firms and 1,594,361 establishments with nonzero employment per 
year, ${ }^{13}$ and it contains information on the municipality in which each establishment is located. However, in 2008, a new form of separation was introduced in France for workers on permanent contracts, the so-called rupture conventionnelle (conventional separation), which reduced the possibility of filing complaints in courts in case of mutually voluntary separations while simultaneously granting access to unemployment benefits to separating workers. There is evidence that in some cases ruptures conventionnelles replaced dismissals, while in some others - for older workers, for examplethey replaced quits (see Minni 2013). Because of this, the number of dismissals - and quits - is hardly comparable before and after 2008. To avoid this problem, we restrict our sample to the years prior to 2008. The location provided by the DADS is unique for each establishment, with a given identifier, because identifiers change when establishments move. As a consequence, the location of any establishment - identified by a given identifier-is timeinvariant. The DADS also contain information on the establishment's age and industry and, consistently available only since 2002, the number of employees excluding apprentices and trainees, as well as the gender and occupational structure of the workforce. Since this information refers to December 31 of each year, and we wish to avoid having controls that are postdated with respect to dismissals, our estimates focus on the period 2003-7.

For each firm in our sample, the DADS provides information on the identifier of its headquarters and the municipality in which it is located. A small proportion of firms in our sample $(8.1 \%)$ report changes in headquarters involving changes in municipalities over time. However, some of these changes are clearly implausible. For example, some firms change headquarters several times between 2003 and 2007, going back and forth between two municipalities. To overcome this problem, we select as the unique headquarters over the sample period the establishment that is most frequently reported to be so. ${ }^{14}$ Finally, the DADS also have information both on the legal category of the firm (commercial company, public administration, charity, etc.) and on firm age.

The second source that we use is the DMMO/EMMO database. The DMMO (Déclarations sur les Mouvements de Main-d'Oenvre) has exhaustive quarterly data on gross worker flows (hirings and separations, excluding temporary help workers) for establishments with 50 employees or more. The data on separations are broken down by type of flow (dismissals, quits, end-of-trial period, end of fixed-term contracts, and retirement). The

${ }^{13}$ These figures show that a wide majority of French firms are mono-establishment and hence outside the scope of our analysis.

${ }^{14}$ When two establishments are equally frequently reported as headquarters, we select as headquarters the establishment reported in the DIANE database, which is provided by Bureau Van Dijk. Our results are robust to excluding all firms whose headquarters change municipality over time. 
EMMO (Enquête sur les Mouvements de Main-d'Oeuvre) has identical information on a representative sample containing $25 \%$ of the establishments with 10-49 employees. ${ }^{15}$ We compute separation rates by type of flow (including dismissal rates) for each quarter during the period 2003-7. For each type of flow, the separation rate is defined as the sum of all separations of that type in a given quarter divided by average employment in that quarter. ${ }^{16}$

Information on the latitude and longitude of municipalities is provided by the Répertoire Géographique des Communes. ${ }^{17}$ Great-circle distances between establishments are computed assuming that each establishment is placed at the barycenter of the municipality to which it belongs. This is, of course, a simplifying assumption, but given that there are 36,570 municipalities in France and that only $0.04 \%$ of them have a surface larger than 190 square kilometers, the error we are making on the actual location is very small. ${ }^{18}$ A consequence of this assumption is that two establishments located in the same municipality are at zero distance from each other by definition. We also have information on the 94 mainland French départements and the 21 mainland administrative regions to which each municipality belongs. Furthermore, the Base Communale des Zones d'Emploi provides information on the "employment areas" where municipalities are located. ${ }^{19}$ These are travel-to-work zones defined on the basis of daily commuting patterns as observed at the beginning of the 1990s. Most employment areas, which correspond to local labor markets, include a city and its catchment area. There are 341 such areas in mainland France, with an average size of 1,570 square kilometers, which represents a relatively fine partition of the French territory.

We match these data sources (DADS, DMMO-EMMO, and geographical databases) and keep all commercial companies registered in France in the nonagricultural, nonmining business sector. ${ }^{20} \mathrm{We}$ only consider multiestablishment firms, and we drop establishments for which dismissal rates

${ }^{15}$ We do not have any information on worker flows for establishments with fewer than 10 employees.

${ }^{16}$ The average employment level in a quarter is defined as half of the sum of the employment levels at the beginning and the end of the quarter (see, e.g., Davis, Faberman and Haltiwanger 2006).

${ }^{17}$ This database is produced by the French Institut National de l'Information Géographique et Forestière (IGN).

${ }^{18}$ All French municipalities but nine are no larger than a square of $14 \times 14$ kilometers. Therefore, assuming that establishments are located at the barycenter implies that the maximum possible error for these 36,561 municipalities is less than 10 kilometers. Moreover, the nine municipalities with a surface larger than 190 square kilometers account for only $0.12 \%$ of the French population altogether.

${ }_{19}$ This database is provided by the French Statistical Institute (INSEE).

20 This corresponds to Sectors 15-74 in the NACE-Rev1 classification. 
or some of our establishment-level controls are missing. Since we wish to compare dismissal rates across the secondary establishments of firms, we only retain companies with at least two secondary establishments in our data set. Our final sample contains 29,508 secondary establishments belonging to 5,019 different firms.

Descriptive statistics for this sample are presented in appendix table A1. Quarterly dismissal rates are, on average, slightly less than 1\% (0.97\%), ${ }^{21}$ marginally higher in construction and services than in the manufacturing and energy sector. Their distribution by employment area is illustrated in appendix figure A1. Blue-collar workers account for one-third of establishment-level employment, while clerks and technicians/supervisors are, respectively, 27\% and $25 \%$, and managers are $15 \%$. Women represent $37 \%$ of the workforce. While $74 \%$ of the establishments belong to the construction and service sectors, $26 \%$ are in the manufacturing and energy industries. Average firm and establishment size-measured as the number of employees per firm or establishment - are 907 and 136, respectively. Most establishments are at least 5 years old $(63 \%),{ }^{22}$ and the average firm age is 23 years. Finally, the average unemployment rate in the employment area during the selected period is $8.41 \%$.

The distributions of headquarters and secondary establishments by employment area are presented in appendix figures A2 and A3, respectively. In our sample, the median and mean numbers of secondary establishments per firm are 2 and 5.88, respectively (see appendix table A2, col. 1). The average distance from secondary establishments to headquarters is 248 kilometers (see appendix table A3). The mean distance to the closest establishment is 44 kilometers, to the second closest, 73 kilometers, and to the farthest establishment, 511 kilometers.

The visibility of a firm in the employment area of its headquarters is assumed to be an increasing function of its share of local employment. We measure this share as of December 31, 2002, in order for it to be predated with respect to our sample. As shown in appendix table A4, the distribution of the firm's share of local employment is quite skewed. Therefore, in our empirical analysis, we capture high visibility with a dummy variable equal

${ }^{21}$ While the largest dismissal episode in an establishment of our sample involved 716 layoffs in a single quarter, the vast majority (99\%) of the episodes in our sample involved no more than 20 layoffs per establishment and quarter.

${ }^{22}$ Establishment age is often missing in the DADS. To preserve sample size, we construct an age variable using the presence of the establishment in previous waves of the DADS. Since our data go back to 1997 only, our age variable is truncated at 5 years, and most establishments are in the oldest age category. However, in our regressions, the coefficient of the dummy variable " 5 years or more" is never significantly different from that of the dummy variable " 4 years old." This is consistent with the results of Haltiwanger, Jarmin, and Miranda (2013), who show that most job flows occur in the earliest years of establishments' life. 
to 1 if the firm belongs to the upper $25 \%$ of the distribution and 0 otherwise. Symmetrically, we capture low visibility with a dummy equal to 1 if the firm belongs to the bottom $75 \%$ of the distribution and 0 otherwise. ${ }^{23}$

Information on generosity in the area where the firm's headquarters are located is obtained from the 1890 Annuaire Statistique de la France, which provides information on total receipts of local secular charity centers as measured, at the département level, in $1887 .{ }^{24}$ We standardize these donations by département-level GDP. ${ }^{25}$ The advantage of measuring generosity using data from more than 1 century ago is that there is no doubt that this measure is exogenous with respect to dismissals in 2003-7.26 However, it has been shown in the literature on charity that the total amount of charitable giving is greater in communities with a larger number of high-income individuals (Card, Hallock, and Moretti 2010). We take this into account by adding département income per capita in all specifications including generosity. By so doing, we make sure that our measure of generosity does not simply capture the relative level of average income of the départements.

Descriptive statistics for generosity and its geographical distribution are shown in appendix table A4 and appendix figure A4. As for visibility, we consider that headquarters are located in high-generosity départements when they belong to the upper $25 \%$ of the donation-to-GDP distribution. Symmetrically, headquarters are considered to be located in low-generosity départements when they belong to the bottom $75 \%$ of the distribution.

\section{The Econometric Model}

\section{A. Dismissals and Distance to Headquarters}

As a first step, we estimate the following relation between dismissal rates in secondary establishments and their distance to the firm's headquarters:

$$
\mathrm{DR}_{i F t}=\beta_{0}+\beta_{1} \mathrm{Dist}_{i}+X_{i F t} \beta_{2}+D_{t}+D_{F}+\varepsilon_{i F t},
$$

${ }^{23}$ A similar measure of firm visibility is used by D'Aurizio and Romano (2013).

${ }^{24}$ The restriction to secular charitable giving is not a limitation in the context of this paper, since in France charitable donations got out of the control of the Church and became mostly secular as early as the mid-nineteenth century (see Association Française des Fundraisers, 2013, “Des hommes et des dons," http://www.fundraisers .fr/page/historique-de-la-profession).

${ }^{25}$ Département-level GDP is provided by Fontvieille (1982). It is measured as of 1864, which is the year closest to 1887 for which such information is available.

${ }^{26}$ At the same time, this measure of generosity is correlated with current generosity as measured by the 2003-10 average ratio of charity donations to taxable income (computed at the level of départements). The estimated correlation coefficient is 0.22 , which is statistically significant at the $5 \%$ level of confidence. The source of current charity donations and taxable income is the French Ministry of Finance. 
where $\mathrm{DR}_{i F t}$ denotes the dismissal rate in establishment $i$ of firm $F$ at time $t$, Dist $_{i}$ is the distance of establishment $i$ to the firm's headquarters, ${ }^{27}$ and $X_{i F t}$ is a vector of establishment-level controls; $D_{t}$ and $D_{F}$ are quarter $\times$ year and firm dummies, respectively. In estimating this relationship, we consider only secondary establishments, and hence we exclude headquarters from our sample, since the latter are functionally different from the former and may then have lower levels of dismissals for this reason.

Distance to headquarters, however, is most likely to be endogenous. Since plants are plausibly not randomly allocated to locations, the observed correlation between dismissals and distance could be driven, at least partially, by the correlation between distance and unobserved plant characteristics. Formally, the error term in equation (5) would then be written as $\varepsilon_{i F t}=\mu_{i}+$ $u_{i F}$, where $\mu_{i}$ is a plant-specific disturbance potentially correlated with Dist $t_{i}$ and $u_{i F t}$ is an error term uncorrelated with the regressors in equation (5). For example, as emphasized by Kalnins and Lafontaine (2013), locating an establishment far away from the firm's headquarters induces various types of costs, in particular information asymmetries and monitoring costs. Rational firms locate establishments so as to minimize costs. Therefore, they open and maintain them far away from headquarters only if the new locations offer advantages that are likely to compensate for the costs - for example, by reducing the cost of serving local demand, getting closer to inputs, experiencing positive agglomeration externalities, or having amenities that will reduce the cost of labor. If these advantages also affect dismissals, the ordinary least squares (OLS) estimates of equation (5) are likely to be biased. To address the potential endogeneity of distance, we need to turn to an instrumental variable (IV) strategy.

This strategy is based on two building blocks: before introducing our instrument, we define the market potential of a firm $F$ and the contribution of plant $i$ to this market potential. In economic geography, a standard measure of the relative advantage of a location in terms of access to demand is Harris's market potential (Harris 1954). This is defined as the sum of the purchasing capacities of surrounding local markets weighted by the inverse of their distance, which typically proxies transportation costs to customers. By analogy, we define the market potential of a multi-establishment firm $F$ as

$$
\mathrm{MPF}_{F}=\sum_{k} \frac{\mathrm{PC}_{k}}{\min _{i \in F}\left\{\text { Dist }_{k i}\right\}},
$$

${ }^{27}$ We use time-varying dismissal rates, although the distance of our establishments to their firm's headquarters is constant over time. We do so because few of our establishments are present in our sample for all quarters over the period 2003-7. Therefore, the quality of the information that we have for an establishment increases with the number of quarters over which it is observed. We take into account the fact that distance does not vary over time through appropriate clustering of our standard errors (see Sec. V.A.). 
where PC stands for the purchasing capacity of local market $k, i$ indexes the establishments of the firm, including the headquarters, and Dist stands here for the distance between establishments and local markets. In other words, the market potential of firm $F$ is the sum of the purchasing capacities of each local market weighted by the inverse of the distance of these markets to the closest establishment of the firm. As is classical in economic geography, we capture purchasing capacity by population, ${ }^{28}$ and we capture local markets by employment areas. ${ }^{29}$ Assuming, for simplicity, that two establishments are not at the same distance from a given local market, market potential, $\mathrm{MPF}$ can be rewritten as

$$
\mathrm{MPF}_{F}=\sum_{i \in F}\left(\sum_{k \in\left\{\operatorname{Dist}_{k i}^{<} \min _{j \in F \backslash\{i\}}\left(\operatorname{Dist}_{k j}\right)\right\}} \frac{\mathrm{POP}_{k}}{\text { Dist }_{k i}}\right),
$$

where POP denotes population and $F \backslash\{i\}$ stands for the set of establishments of $F$, excluding $i$. The term in parentheses can be interpreted as the contribution of establishment $i$ to the market potential of firm $F(\mathrm{CMPF})$, that is,

$$
\mathrm{CMPF}_{i}=\left(\sum_{k \in\left\{\operatorname{Dist}_{k i}^{<}<\min _{j \in F \backslash\{i\}}\left(\text { Dist }_{k j}\right)\right\}} \frac{\mathrm{POP}_{k}}{{\overline{\operatorname{Dist}_{k i}}}}\right) .
$$

This contribution can be seen as a proxy of the relative size of the local demand served by each establishment.

Having defined the contribution to the firm's market potential, we can present our IV strategy. We use as an instrument the potential distance, defined as the distance to headquarters at which an establishment would have been had its location (called the potential location) been chosen by the firm only in order to maximize its contribution to market potential - that is, disregarding any distance-related costs other than transportation costs to customers - taking the position of the other establishments of the firm as given.

In practice, for each firm in our sample, we pick up one of its secondary establishments and remove it. We then consider each employment area in France and consider what would be the contribution to the firm market potential if an additional plant were located there. We take the employment area

${ }^{28}$ In the economic geography literature, purchasing capacity is proxied either with income-based measures (see, e.g., Combes, Mayer, and Thisse 2008) or with population-based measures (see, e.g,. Bottazzi and Peri 2003; Ioannides and Overman 2004; Briant, Combes, and Lafourcade 2010). We use a population-based measure insofar as information on aggregate income is not available at the level of employment areas.

${ }_{29}$ We exclude foreign markets for which we have no data. 
that maximizes this contribution and measure the distance between its barycenter and the headquarters. We call this potential distance. To qualify as a valid instrument, this variable must affect dismissals only through distance and should therefore be uncorrelated with any unobserved plant-specific characteristics that can affect dismissals after conditioning on distance.

To show that this is the case, we need to be more specific on how we construct potential distance. Formally, potential location (PL) is defined as

$$
\mathrm{PL}_{i}=\underset{b}{\operatorname{argmax}}\left\{\mathrm{CMPF}_{h}\right\},
$$

where $h$ indexes the employment areas, and potential distance is the distance from PL to the firm's headquarters. Defined in this way, potential distance is, by construction, unrelated to any component of the plant-specific disturbance $\mu_{i}$ that is not correlated to the CMPF, except if local population and dismissals are correlated, for example if people tend to migrate away from depressed areas. To overcome this problem, scholars in economic geography have used local terrain ruggedness as an exogenous predictor of population (see Combes et al. 2010; Nunn and Puga 2012). The idea is that it is more difficult to settle in more rugged locations. Taking the maximum value of ruggedness in our data minus the effective ruggedness of the area as an exogenous proxy of population,,$^{30} \mathrm{PL}$ can be written as

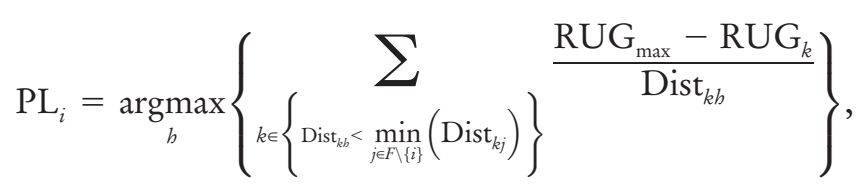

where $\mathrm{RUG}_{k}$ denotes ruggedness of the employment area $k$ and $\mathrm{RUG}_{\max }$ is the maximum ruggedness over all employment areas.

When potential location is given by equation (6), there is no reason that potential distance affects dismissals except through actual distance or because it could be correlated with local demand as measured by the CMPF. This would be a problem if the CMPF simultaneously affected potential distance and dismissals. However, we show below that potential distance and $\mathrm{CMPF}_{i}$ are uncorrelated. We conclude from this that our exclusion restriction is likely to hold.

We compute the contribution of establishment $i$ to the market potential of firm $F$ assuming that all other establishments of $F$ are located at the barycenter of their region. This simplifying assumption allows us to save substantial computational time, since some of our firms have a few thousand

${ }^{30}$ Following Combes et al. (2010), local terrain ruggedness is defined here as the mode of maximum altitudes across all pixels in an employment area minus the mode of minimum altitudes, using pixels of 1 kilometer by 1 kilometer. The correlation between ruggedness and population across employment areas is significant at the $1 \%$ level in our data. 
Table 1

Correlation between Potential Distance to Headquarters and Contribution to Market Potential (CMPF)

\begin{tabular}{lcc}
\hline & 1999 Population & 2009 Population \\
& $(1)$ & $(2)$ \\
\hline Full sample & -.010 & -.006 \\
& $(.927)$ & $(.957)$ \\
Excluding sea and border départements & .014 & .018 \\
& $(.916)$ & $(.893)$ \\
\hline
\end{tabular}

NOTE.-CMPF is based on 1999 and 2009 population data in cols. 1 and 2, respectively. Variables are in deviation from the firm average; $p$-values are in parentheses. Significance is obtained adjusting for clustering at the level of the département of the headquarters.

establishments. ${ }^{31}$ The first row in table 1 shows that the correlation between potential distance and CMPF is virtually zero, independently of whether we use the population in 1999 or in 2009 to compute CMPF.

One potential problem with our computation of CMPF is that it is heavily underestimated for the establishments located close to the sea or to a foreign country. For these, local demand should indeed include nearby areas in border and/or overseas countries for which, unfortunately, we do not have any information. Failure to account for these areas generates measurement error, which biases the correlation between the CMPF and potential distance toward zero. To solve this problem, we compute this correlation on the subsample of establishments located in départements that have no border with the sea or any foreign country, using the fact that the contribution of each employment area to CMPF is weighted by the inverse of distance (see eq. 6), so that the measurement error due to the omission of foreign markets decreases quickly when moving away from the sea and borders. When using this restricted sample, we find very similar results: whatever the population used to compute CMPF (as of 1999 or as of 2009), the coefficients of correlation with potential distance are lower than 0.02 and statistically insignificant at conventional levels. ${ }^{32}$

31 The largest firm in our sample has 3,163 establishments, most of them with fewer than 10 employees (see table A2, col. 2). We do not have worker flows for plants smaller than 10 employees (see Sec. III). Therefore, plants of this size are not included in our regression analysis, so the maximum number of plants included in our regression sample and belonging to the same firm is 863 (see table A2, col. 1). However, we take their location into account to compute the contribution to the firm's market potential of the plants in our sample.

${ }^{32}$ In contrast, the actual distance to headquarters turns out to be positively correlated with CMPF: whatever the population used to compute the latter, we find a coefficient of correlation as high as 0.17 . This suggests that establishments located far away from their headquarters are selected on their contribution to market potential. As hypothesized by Kalnins and Lafontaine (2013), this may be due to the fact that they incur higher costs (e.g., monitoring costs), which have to be compensated by a greater contribution to the firm's market potential. 


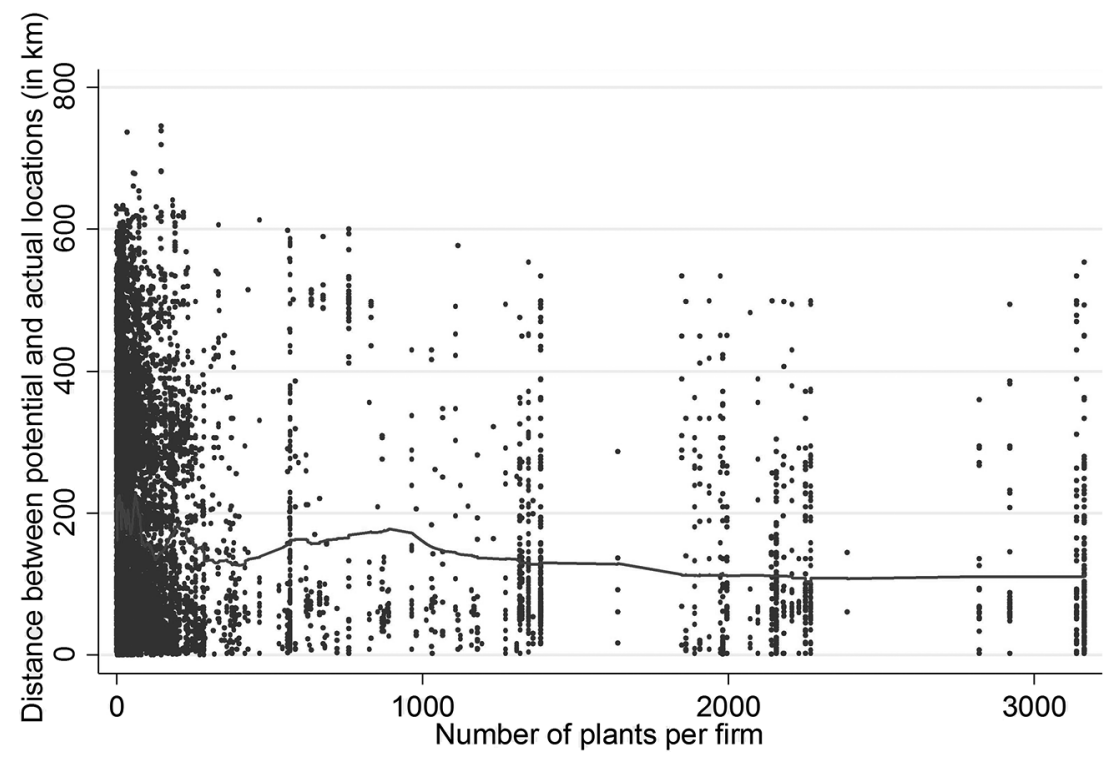

FIG. 2.-Distance between actual and potential locations as a function of the number of plants per firm. The solid line represents a local mean smoothing obtained with a $5 \%$ bandwith and Cleveland's tricube weighting function. A color version of this figure is available online.

In the construction of the instrument, taking the location of all establishments but one as given imposes restrictions on the places where the potential location can be. This might be a problem for firms with a large number of plants, as these restrictions may imply that potential and actual locations either coincide or are very close. To dispel this concern, we plot in figure 2 the distance between actual and potential locations against the number of plants in the firm. Even for firms with more than 500 establishments, we find that the distance between actual and potential locations is far from being systematically small.

\section{B. The Role of Social Pressure}

Having established that distance to headquarters has a positive impact on dismissals in secondary establishments, we investigate the role of local social pressure at headquarters in generating this relation. As suggested by the simple model proposed in Section II, if social pressure is a key determinant of the distance-dismissal relationship, we expect the latter to be stronger the greater the firm visibility at headquarters and the lower the generosity of the local community.

As a first step, we test whether the impact of distance on dismissals varies with firm visibility at headquarters. In order to do so, we estimate the following equation: 
$\mathrm{DR}_{i F t}=\beta_{\mathrm{LV}}$ Dist $_{i} \times \mathrm{LV}_{F}+\beta_{\mathrm{HV}}$ Dist $_{i} \times \mathrm{HV}_{F}+X_{i F t} \gamma+D_{t}+D_{F}+\varepsilon_{i F t}$,

where $\mathrm{LV}_{F}$ and $\mathrm{HV}_{F}$ denote low and high visibility of the firm at headquarters, respectively. If more visible firms are more sensitive to social pressure, we expect $\beta_{\mathrm{HV}}$ to be larger than $\beta_{\mathrm{LV}}{ }^{33}$

As a second step, we focus on the impact of generosity. We investigate whether the positive relationship between dismissals and distance to headquarters is stronger when firms' headquarters are located in areas where the local community is more selfish (less generous). We estimate:

$\mathrm{DR}_{i F t}=\beta_{\mathrm{LG}} \mathrm{Dist}_{i} \times \mathrm{LG}_{F}+\beta_{\mathrm{HG}}$ Dist $_{i} \times \mathrm{HG}_{F}+X_{i F t} \gamma+D_{t}+D_{F}+\varepsilon_{i F t}$,

where $\mathrm{LG}_{F}$ and $\mathrm{HG}_{F}$, respectively, denote low and high generosity of the community in which the firm's headquarters are located, and where we expect that $\beta_{\mathrm{LG}}>\beta_{\mathrm{HG}}$.

We also check whether the impact of firm visibility on the positive relationship between distance to headquarters and dismissals increases as the local community of the firm's headquarters becomes less generous. More specifically, we estimate:

$$
\begin{aligned}
\mathrm{DR}_{i F t}= & \beta_{\mathrm{LG}_{-} \mathrm{LV}} \mathrm{Dist}_{i} \times \mathrm{LG}_{F} \times \mathrm{LV}_{F}+\beta_{\mathrm{LG}_{-} \mathrm{HV}} \mathrm{Dist}_{i} \times \mathrm{LG}_{F} \times \mathrm{HV}_{F} \\
& +\beta_{\mathrm{HG} \_\mathrm{LV}} \text { Dist }_{i} \times \mathrm{HG}_{F} \times \mathrm{LV}_{F} \\
& +\beta_{\mathrm{HG} \_\mathrm{HV}} \text { Dist }_{i} \times \mathrm{HG}_{F} \times \mathrm{HV}_{F}+X_{i F t} \gamma+D_{t}+D_{F}+\varepsilon_{i F t}
\end{aligned}
$$

and expect $\beta_{\mathrm{LG}_{-} \mathrm{HV}}$ to be positive and larger than any other $\beta$ coefficient and, in particular, than $\beta_{\mathrm{LG} \_\mathrm{LV}}$.

\section{Results}

\section{A. Dismissals and Distance to Headquarters}

The impact of distance to headquarters on dismissals (see eq. [5]) is first estimated by OLS, using a "selection on observables" approach, which tries to capture plant-specific effects with a vector of observables. Our baseline specification includes time and firm dummies and the following establishment characteristics: industry and employment-area dummies, establishment size and age dummies, gender and occupational structure of the workforce, firm size in the establishment's local labor market (i.e., the employment area where the establishment is located), and time-varying unemployment rates in the employment area. We control for employment-area dummies, since, together

${ }^{33}$ Strictly speaking, our model predicts that $\beta_{\mathrm{HV}}>\beta_{\mathrm{LV}}$ only for levels of generosity that are sufficiently low. For higher values of the generosity parameter, the model yields ambiguous predictions as to the relative values of $\beta_{\mathrm{HV}}$ and $\beta_{\mathrm{LV}}$. 
with firm dummies, they capture the relative attractiveness of the establishment's location. Establishment size is important because large establishments may be located closer to headquarters and because it may be easier for them to reallocate workers internally and hence avoid dismissals. Moreover, transfers across plants within the same local labor market are probably not resisted by workers, so relocating unnecessary workers is easier for the firm if it is of large size in the area where the establishment is located. This is why we also control for firm size in the establishment's employment area. Controlling for establishment age is motivated by the fact that, as shown by Neumark, Zhang, and Ciccarella (2008) in the case of Wal-Mart, establishments located further away from headquarters are likely to be younger and to have more volatile activity ${ }^{34}$ which generates more dismissals. We control for workforce characteristics because the frequency of dismissals may differ across gender and/or occupation. Local unemployment rates capture the fact that, beyond fixed local labor market characteristics, establishments located further away from headquarters may be affected by negative temporary shocks and hence dismiss more workers.

The OLS estimates obtained with this specification are presented in column 1 of table 2. In this table, as in all others, we cluster standard errors at the level of the département where the firm headquarters are located. We do so because our model suggests that social pressure matters and varies with the characteristics of the local communities. So we need to take into account the fact that establishments from different firms with headquarters located in the same département (or employment areas) are affected in the same way by social pressure. We therefore cluster our standard errors at the most aggregate local level (i.e., the département of the headquarters). ${ }^{35}$

We find that distance to headquarters has a positive and significant effect on dismissals: when the former increases by 100 kilometers, dismissals increase by 0.03 percentage points, that is, by $3.33 \%$, as measured at the sample average. Note that if we add headquarters to our sample and include a dummy variable for them in the baseline specification, our results are virtually unchanged, with a point estimate (SE) of 0.029 (.012).

A problem with "selection on observables," the approach taken in the first column of table 2 , is that the omission of plant-specific effects that are correlated both with distance and with dismissals may produce biased estimates of the true correlation between distance and dismissals. We deal with this problem by using the IV strategy described in Section IV.A, where the actual distance to headquarters is instrumented by the potential distance

\footnotetext{
${ }^{34}$ On the relationship between age and volatility, see also Haltiwanger et al. (2013).

35 This is all the more meaningful that in France, the département is traditionally considered as the relevant geographical level for solidarity (see, e.g., Michel Waintrop, "Des départements protestent contre la réforme des plaques d'immatriculation," La Croix, January 28, 2008).
} 
Table 2

Distance to Headquarters and Dismissals in Secondary Establishments 2003-7

\begin{tabular}{|c|c|c|c|c|}
\hline & $\begin{array}{l}\text { OLS } \\
(1)\end{array}$ & $\begin{array}{l}\text { OLS } \\
(2)\end{array}$ & $\begin{array}{l}\text { IV-First Stage } \\
\text { (3) }\end{array}$ & $\begin{array}{c}\text { IV-Second Stage } \\
(4)\end{array}$ \\
\hline Sample & Full & $\begin{array}{l}\text { No sea and } \\
\text { border }\end{array}$ & $\begin{array}{l}\text { No sea and } \\
\text { border }\end{array}$ & $\begin{array}{l}\text { No sea and } \\
\text { border }\end{array}$ \\
\hline Dependent variable & Dismissal rate & Dismissal rate & Distance to HQ & Dismissal rate \\
\hline Distance to headquarters & $\begin{array}{l}.033 \% \\
(.015)\end{array}$ & $\begin{array}{l}.062 \% \% \\
(.018)\end{array}$ & & $\begin{array}{l}.064 * \% \\
(.025)\end{array}$ \\
\hline $\begin{array}{l}\text { Potential distance to } \\
\text { headquarters }\end{array}$ & & & $\begin{array}{l}.522 \% \% \\
(.239)\end{array}$ & \\
\hline $\begin{array}{l}\text { Angrist-Pischke } F \text {-test } \\
\text { for distance } \\
\text { to headquarters }\end{array}$ & & & 4.76 & \\
\hline Observations & 272,021 & 145,306 & 145,306 & 145,306 \\
\hline$R^{2}$ & .114 & .186 & .811 & .002 \\
\hline Control variables? & Yes & Yes & Yes & Yes \\
\hline
\end{tabular}

NOTE.-In all columns except col. 3 , the dependent variable is the quarterly dismissal rate in percentage multiplied by 100. Control variables include firm, industry, time and employment-area dummies; the unemployment rate in the employment area of the establishment; the occupational and gender structure of the workforce; establishment age and size dummies; and dummies for firm size in the employment area of the establishment. Robust standard errors clustered at the level of the département of the headquarters are in parentheses. IV models are estimated with two-stage least squares estimators.

$\because * p<.05$.

$* * * 0<1$.

at which the establishment would have been located had its location been chosen by the firm only to maximize its contribution to its market potential.

This instrument, however, is likely to be affected by substantial measurement error for plants located in départements that are on the seaside or that have borders with foreign countries. As discussed in Section IV.A, this is due to the fact that in these locations the contribution to the firm market potential (CMPF) is heavily underestimated because local demand depends to a larger extent than in other locations on border and/or overseas countries for which we have no information. ${ }^{36}$ When we regress actual on poten-

${ }^{36}$ It is useful to illustrate this point further with an example. Assume that a firm has its headquarters in Paris and two plants, one in the very center of France-say, Clermont-Ferrand - and the other close to the Belgian border-say, in Lille. If we were to correctly compute the potential location associated with the second plant, we should consider as relevant local markets not only the French but also the Belgian employment areas bordering the French territory. By omitting these densely populated Belgian areas, for which we have no data, we may identify a location in the South of France as the potential location, whereas if we had been able to include these areas in our computation, the potential location would have been close to Lille. In the case of Clermont-Ferrand, instead, the choice of the potential location is much less likely to be affected by the omission of border Belgian areas. 
tial distance using the subsample of locations on the seaside or with borders with foreign countries, we find that the estimated relation is nonmonotonic, ${ }^{37}$ which violates the monotonicity assumption required by the LATE theorem (see, e.g., Angrist and Pischke 2009a). In contrast, there is no evidence of any nonmonotonicity in the subsample that excludes the plants in these locations. ${ }^{38}$ Therefore, we restrict our IV estimation to this reduced sample.

We first check that this sample restriction does not modify our baseline OLS results. As shown in column 2 of table 2, the impact of distance to headquarters on dismissals is still positive and significant at the $1 \%$ level. In the next column, we report the first-stage estimates when potential distance is used as an instrument for actual distance. We find that the effect of the former on the latter is positive and statistically significant at the $5 \%$ level of confidence. Although the $F$-test statistic on the instrument is somewhat low (4.76), we rely on two properties of 2SLS estimators in just identified models such as ours (see Angrist and Pischke 2009b): first, these estimators are median-unbiased; second, the estimated confidence intervals are reliable except when the $F$-test statistic is very close to 0 . This suggests that we can confidently make inferences on the basis of second-stage estimates (see col. 4). The estimated IV coefficient of distance is very close to the OLS coefficient (0.064 vs. 0.062 ) and statistically significant at the $5 \%$ level. ${ }^{39}$ The finding that the IV point estimate is almost identical to the OLS estimate suggests that selection on observables as implemented in columns 1 and 2 of the table does a reasonably good job in capturing the causal effect of distance on dismissals. This is not surprising because by including very detailed employment-area and firm dummies we can control for most sources of locational advantage.

Next, we present a number of robustness checks of the baseline specification..$^{40}$ To start with, one could worry that the positive impact of distance to headquarters on dismissals could be entirely driven by the effect at short distances and disappear at long distances. As can be seen in appendix table A5,

\footnotetext{
${ }^{37}$ When regressing actual on potential distance and its square using the sample of plants located in border and sea départements and using the same controls as in table 2, we find that the point estimates for potential distance and potential distance squared are -0.278 (with $\mathrm{SE}=0.142$ ) and 0.0009 (with $\mathrm{SE}=0.0003$ ), respectively, suggesting that the relationship between potential and actual distance changes sign at 157 kilometers.

${ }^{38}$ When regressing actual distance on any polynomial in potential distance up to the fifth order, none of the terms of order higher than one is ever significant at conventional levels.

${ }^{39}$ Given the key role of Paris in the French economy, we check that our results are robust to excluding the Paris area from our sample. It turns out that both OLS and IV estimates are very close to those obtained for the full sample (reported in cols. 1 and 4): the coefficients estimated by OLS (IV) are $0.036(0.068)$, with SE = $0.015(\mathrm{SE}=0.026)$.

${ }_{40}$ To take advantage of the larger sample, these robustness checks-as well as those in the following subsection-are performed using OLS estimates.
} 
however, this is not the case, since the point estimate of distance to headquarters is almost unchanged when dropping establishments located at short distances, that is, at less than 50 kilometers and 100 kilometers, respectively (see cols. 1 and 2). ${ }^{41}$ To give a more precise picture of the impact of distance on dismissals we re-estimate our model using distance bins of 100 kilometers. As shown in column 3 of the table, dismissal rates tend to be larger the greater the distance to headquarters, even though there is much heterogeneity in the effect of the latter. Finally, we check that our results are robust to using the $\log$ - rather than linear-distance to headquarters. Given that $6 \%$ of our establishments are located in the same municipality as their headquarters and hence have zero distance to headquarters (see Sec. III), we consider a specification that uses $\log (1+$ distance $)$. As shown in column 4 of the table, the impact of distance to headquarters on dismissals is positive and significant at the $5 \%$ level. $^{42}$

A second concern is that our results could be driven by the large proportion of zero dismissal rates in our sample and the fact that equation (5) does not account for the censoring of the distribution of dismissal rates at 0 . We address this problem by estimating a Tobit model, using the Mundlak transformation to control for firm fixed effects. Results, however, are qualitatively similar to the baseline (see col. 5 in table A5).

Finally, we check that our results are homogeneous across industries by interacting distance to headquarters with a dummy variable for the manufacturing and energy sectors. This interaction turns out to be insignificant at conventional levels (see table A5, col. 6), thus suggesting that the distancedismissal relationship is essentially homogeneous across manufacturing and energy on the one hand and construction and services on the other hand.

The relatively low level of dismissals at short distances from headquarters could be compensated by other types of separations. We therefore examine the effects of distance on quits, retirement, trial-period, and fixed-term-

${ }^{41}$ The fact that the distance-dismissal relationship does not disappear at long distances is consistent with the pattern of social relations uncovered when using the Contact entre les personnes survey (see footnote 12): the intensity of social relations decreases with distance between individuals, and the negative correlation does not become insignificant even when eliminating individuals located at less than $250 \mathrm{ki}-$ lometers, which is the average distance between a plant and its headquarters in our sample. This suggests that individuals have fewer contacts with relatives and friends located further away and that this holds at long as well as at short distances.

${ }_{42}$ This specification is not the one we prefer because the log function is too flat to properly fit the distance-dismissal relationship at long distances: when dropping establishments at less than 50 kilometers from their headquarters and re-estimating the specification in col. 4, we get a much larger coefficient: 9.130, with $\mathrm{SE}=3.434$. As we have seen in col. 1 of table A5, this is not the case with the linear distance, since the point estimate obtained when dropping the closest distances is roughly equal to the one we get on the whole sample. Linear distance is thus our preferred specification. 
contract terminations (see appendix table A6). None of these separations appear to vary with the distance to the headquarters.

Our model predicts that the effect of social pressure on dismissals should also be reflected in the behavior of firms regarding hirings on permanent contracts. Unfortunately, the data we have at hand do not allow us to test this assumption properly. Our database contains two types of hiring data, one including only direct hires on permanent contracts and the other encompassing all hires, including those on fixed-term contracts, who represent more than $80 \%$ of all hires but are irrelevant for our purpose. Unfortunately, direct hires on permanent contracts are not a good measure of total hirings on this type of contracts either. In France, fixed-term contracts are indeed partly used as a way to circumvent legal limitations on the duration of the probationary period due to the fact that these contracts can be as long as 18 months, including renewals, while the probationary period of a permanent contract cannot be longer than 3-8 months, depending on the occupation. As a consequence, many workers are hired on fixed-term contracts and only subsequently their contract is converted into a permanent one. Information on conversions, however, is not available in our data. ${ }^{43}$ In principle, our model should be tested on the sum of direct hires on permanent contracts plus conversions (i.e., all new permanent contracts). Using only direct hires on permanent contracts as a proxy for total hires would generate a measurement error bias when estimating the relationship between distance to headquarters and hirings on permanent contracts, and this bias is likely to vary with distance. ${ }^{44}$ Given these problems, we refrain from estimating the relationship between distance and hirings.

\section{B. Social Pressure and Dismissals}

We have established above that plants located further away from their headquarters have higher dismissal rates. In this subsection, we investigate

${ }^{43}$ Nonetheless, looking at statistics at the national level suggests that the number of conversions is significant: the number of hires on fixed-term contracts is much larger than that of ends of fixed-term contracts (the difference being as large as $35 \%-40 \%$ of dismissals in French plants with more than 10 employees). This difference is due to conversions that we cannot measure.

${ }^{44}$ For example, a sorting/selection argument suggests that direct hires on permanent contracts increase with distance more than all new permanent contracts do. The reason is that a job located far away from the firm headquarters is unlikely to be considered a "very good" job because career opportunities are better close to the headquarters. Therefore, firms are likely to offer permanent contracts more frequently in establishments located far from headquarters as a way to attract good workers. Symmetrically, firms are more likely to use conversions from fixed-term to permanent contracts in establishments close to headquarters. This implies that should we run our estimates on the direct-hiring-on-permanent-contract data that we have, the results would be affected by an error systematically related to our explanatory variable and possibly generating an upward bias. 
the role of social pressure at headquarters in generating the observed geographical pattern of dismissals.

As shown by our model, at least conditional on a sufficient degree of selfishness, if the positive impact of distance on dismissal rates results from social pressure, it should be stronger wherever the firm represents a larger share of employment in the local labor market (i.e., the employment area) where its headquarters are located. In that case, the firm is indeed more visible in the community of its headquarters, which increases the CEO's incentive to avoid painful adjustments in closely located establishments. We test this prediction by estimating equation (7) (see table 3). As shown in column 1, the impact of distance to headquarters on dismissals is significantly larger for high-visibility firms than for low-visibility firms, ${ }^{45}$ suggesting that whenever firms are more visible in the area where their headquarters are located, they are more reluctant to fire workers close to headquarters.

One source of concern, however, is that our results might be driven by the fact that firms that are highly visible at headquarters are simply large firms in the local area of their headquarters. If unions are more powerful where firms are larger, the stronger relationship between distance and dismissals for high-visibility firms could be due to the ability of unions to avoid local dismissals rather than to the visibility of the firm and local social pressure arising from outside the firm. We show that this alternative interpretation is not supported by our data, as the impact of distance on dismissals remains much larger for firms with high visibility at headquarters than for firms with low visibility, even after controlling for the interaction between distance to headquarters and total (absolute) firm size in the employment area of the headquarters (see col. 2 in table 3 ).

Other confounding factors may be correlated both with dismissals and with the interaction between distance and firm visibility. First, highly visible firms may also be more concentrated at headquarters. If CEOs dispose of better-quality information wherever firms' activities are more concentrated, they may be more able to use internal reallocations rather than dismissals to adjust employment at short distances, which may induce a spurious correlation between dismissals and the interaction between distance and firm visibility. Second, firms that are mostly active in the manufacturing and energy sectors tend to be more visible at headquarters: their average share of employment in the area of their headquarters is $0.46 \%$ as compared to $0.16 \%$ in construction and services. If the former suffer more from monitoring problems in distant plants than firms in the service sector do, our results could capture composition effects across industries. As shown in table 3 , column 3 , these confounding factors do not account for our results,

${ }^{45}$ The number of observations is lower in table 3, cols. 1-3, than in table 2 because, for some firms, the information on their size at headquarters is missing for 2002. 


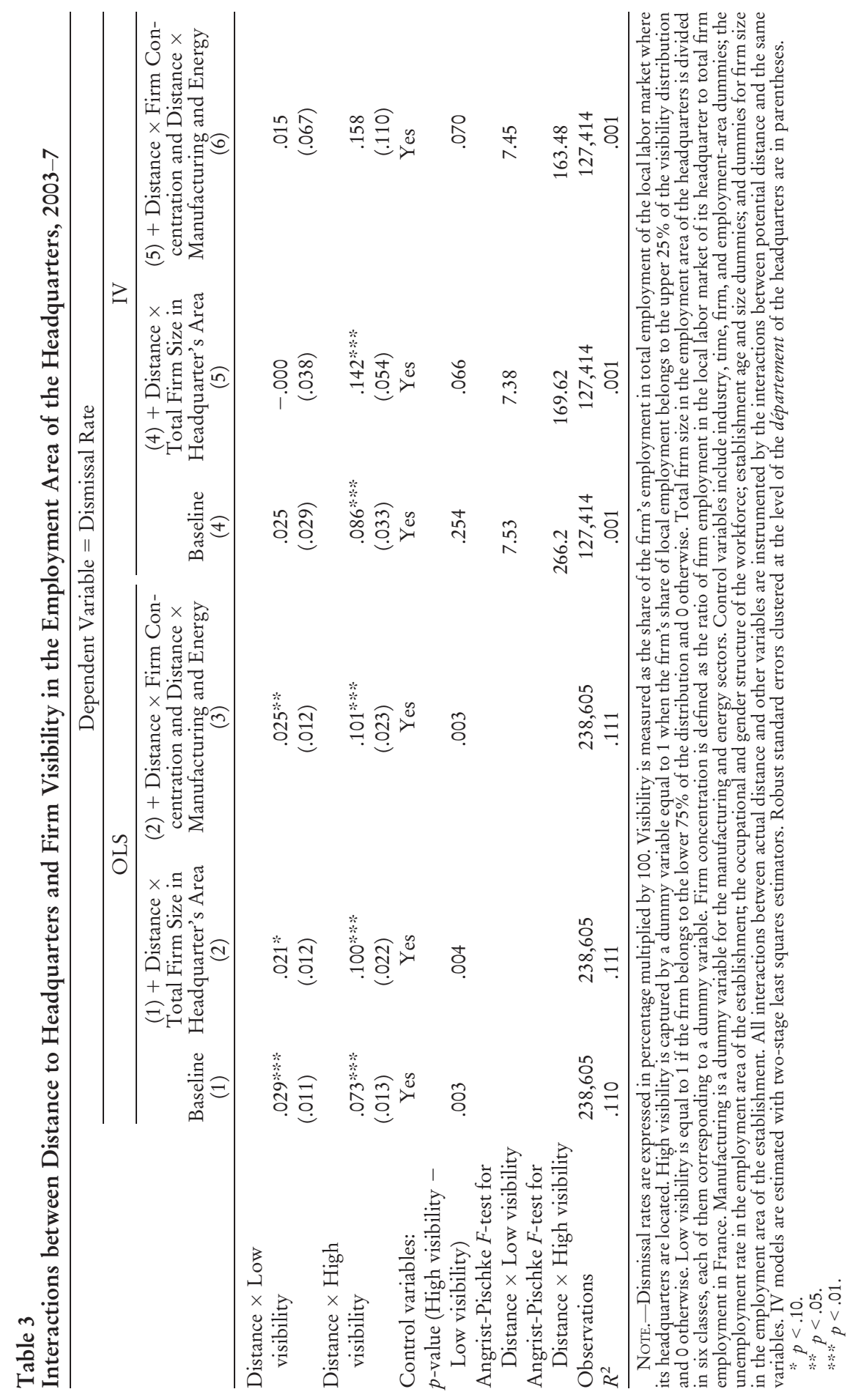


since the distance-dismissal relationship remains stronger when firms are highly visible at headquarters, even after controlling for the interaction between distance and manufacturing an energy, on the one hand, and distance and firm concentration in the employment area of the headquarters, ${ }^{46}$ on the other hand.

Equation (7) is then re-estimated by IV. All interactions between actual distance and other variables are instrumented by the interactions between potential distance and the same variables. ${ }^{47}$ The results are, of course, less precise, but in the most complete specifications, columns 5 and 6, the impact of distance to headquarters on dismissals remains significantly larger for high-visibility firms than for low-visibility firms (at the $10 \%$ level of confidence) ${ }^{48}$

Our hypothesis is that what matters for dismissal decisions is the social pressure borne by the $\mathrm{CEO}$ at headquarters, that is, in his/her local environment. In our model, the CEO's utility is not affected by social pressure arising from local communities of secondary establishments. If this is true, only firm visibility at headquarters should matter, and dismissals should be essentially unaffected by firm visibility in the area where the plant is located. We test this assumption in two different ways. First, we re-estimate equation (7) including a dummy variable indicating high firm visibility in the employment area of the plant and an interaction between distance to headquarters and this dummy variable. If social pressure in the local community of the plant mattered, we would expect it to counterbalance the impact of social pressure at headquarters. In this case, the interaction between distance to headquarters and high visibility at the plant should have a negative and significant impact on dismissals. Yet, we find that the point estimate on the distance $\times$ high-visibility-at-plant interaction is almost $0(-0.0003$ with $\mathrm{SE}=0.0150)$. Moreover, controlling for this interaction does not modify the estimated impact of visibility at headquarters on the distance-dismissal relationship. ${ }^{49}$ This suggests that, when taking dismissal decisions, CEOs

${ }^{46}$ Concentration is defined here as the ratio of firm employment in the local labor market of its headquarters to total firm employment in France.

${ }^{47} \mathrm{We}$ do the same in all the IV models of this subsection.

${ }^{48}$ As suggested by Angrist and Pischke (2009a), we test for the weak identification of each endogenous variable using partial $F$-tests (reported in table 3 ). Given that our models have as many instruments as endogenous variables, they are just identified. As mentioned in Subsec. V.A, just-identified two-stage least squares estimators are median-unbiased and confidence intervals are reliable, except when the Angrist-Pischke $F$-test statistics are very close to 0 .

${ }_{49}$ Point estimates comparable to those provided in table 3, col. 3, are obtained by defining, in this specification, the interaction between distance to headquarters and high visibility at plant in deviation from sample mean. The point estimate on the interaction between distance to headquarters and high (respectively, low) firm visibility at headquarters is then $0.090(0.015)$ with $\mathrm{SE}=0.027(\mathrm{SE}=0.015)$, hence very similar to those obtained in table $3, \mathrm{col} 3)$. 
are influenced by social pressure, but only when exerted in their local environment and not when arising from more remote communities.

We provide additional evidence on this by implementing a placebo test. We define as placebo headquarters the largest establishment located in the employment area where the firm is the most visible (excluding that of the true headquarters). ${ }^{50}$ We then estimate equation (7) using these placebo headquarters (and excluding the true ones). We find no significant impact on dismissals of either distance to the placebo headquarters (see appendix table A7, col. 1) or of distance interacted with firm visibility at the placebo headquarters (see col. 2). Results do not vary if we define as placebo headquarters a secondary establishment randomly drawn from all the establishments of the firm located outside the employment area of the true headquarters (see table A7, cols. 3 and 4). These estimates suggest that firm visibility in the local labor market of secondary establishments does not affect dismissals, whereas visibility at headquarters does.

These findings support the idea formalized in our stylized model that establishments located further away from headquarters experience higher dismissal rates because CEOs expect dismissals to be more costly at short distances from headquarters due to potential social sanctions in their local environment. One mechanism that accounts for this effect is that people living in the area of the headquarters put pressure on CEOs to avoid dismissing people living close to this area, considering that this would have negative social consequences in their neighborhood. In this framework, the relationship between distance and dismissals hinges on the fact that people living close to headquarters are selfish and value dismissals at short distance more negatively than dismissals far away because the former are more likely to affect them. As a consequence, the greater the selfishness of a community, the greater is the steepness of the distance-dismissal relationship. To test this prediction, we estimate equation (8) using the 1887 ratio of départementlevel charity donations to GDP as an indicator of generosity ${ }^{51}$ When running OLS estimates, we find that the positive impact of distance on dismissals is statistically significant only for firms with headquarters located in low-generosity départements and that the estimated effect of distance on dismissals is significantly larger for low-generosity départements than for high-generosity départements (see table 4, col. 1).

A source of concern is that generosity in a département might capture other local characteristics. This would be the case, for example, if religious

${ }^{50}$ For $56 \%$ of our firms, the employment area where the firm is the most visible is not that of the headquarters.

${ }^{51}$ As discussed in Sec. III, this specification includes distance to headquarters interacted with income per capita to control for the fact that richer areas are likely to be more generous. Taxable income per capita in 1998 is provided by DGFiP-French Ministry of Finance. 


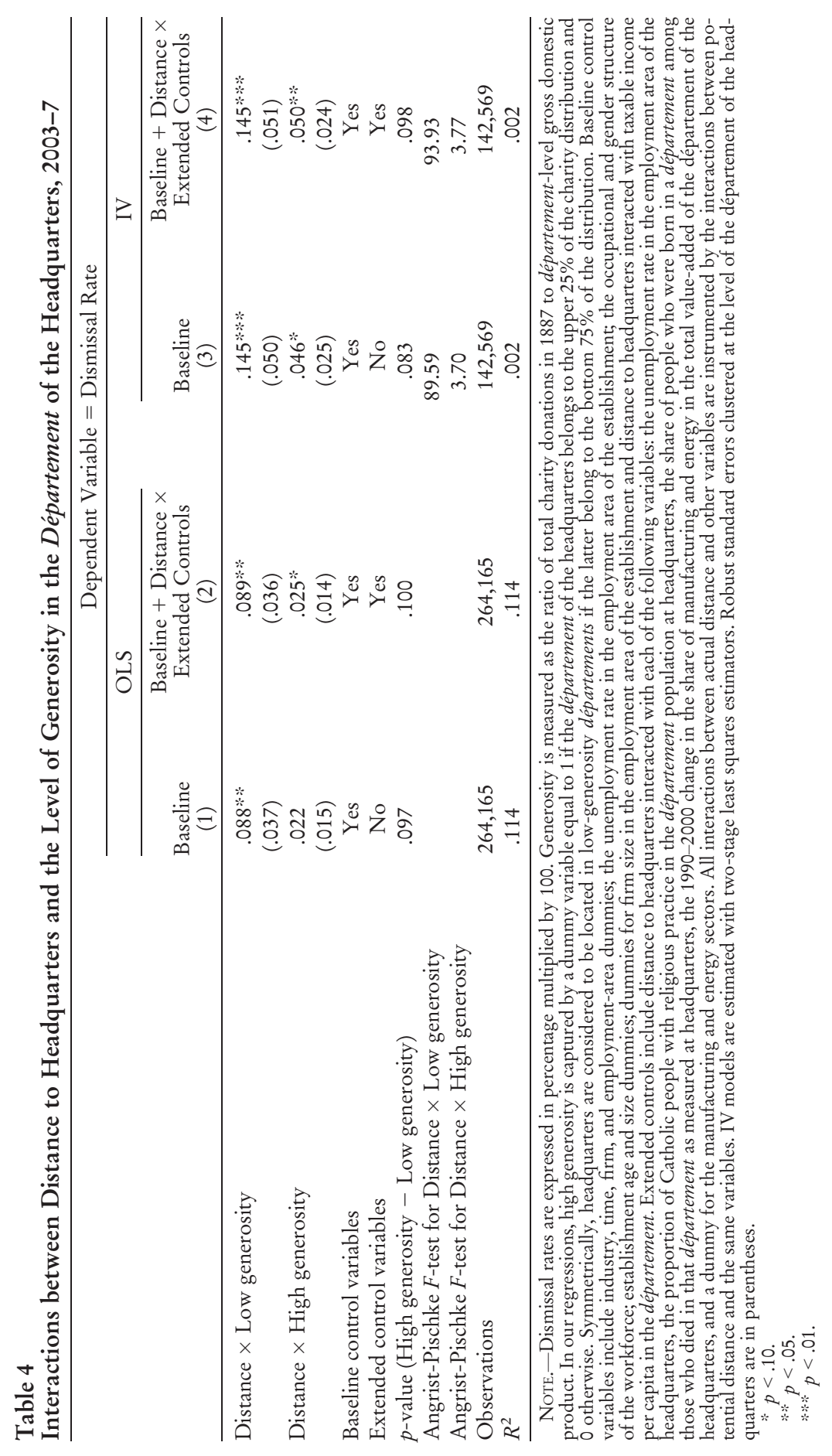


people tended to make larger charitable donations than others. We control for this potential confounder by including in our specification the interaction between distance to headquarters and the proportion of churchgoing Catholics in the population of the département where the headquarters are located ${ }^{52}$ as measured in $2005-9$. Low generosity could also be a consequence of local deprivation. To account for this possibility, we proxy deprivation with local unemployment. Beyond deprivation, local generosity may also be affected by migrations and by changes in the local economic structure. We proxy the proportion of individuals with local origins with the share of people who were born in a département among those who died in that département in 2013. Changes in the local economic structure are measured by the change in the share of manufacturing and energy in total value-added between 1990 and 2000. All these variables ${ }^{53}$ are measured in the département of the headquarters. ${ }^{54}$ To control for these potential confounders, we re-estimate equation (8) including the interactions between distance to headquarters and all the above-mentioned controls. In addition, we also include an interaction between distance and a dummy variable for the manufacturing and energy sectors to account for the fact that the sensitivity of the distance-dismissal relationship to local generosity could vary with the type of economic activity. The results of this extended specification are presented in table 4, column 2. The positive impact of distance on dismissals turns out to be statistically significant for firms with headquarters located both in low-generosity and high-generosity départements, but the effect is larger for low-generosity départements than for highgenerosity départements. The estimated difference is statistically significant at the $10 \%$ level of confidence. ${ }^{55}$

When the baseline and extended specifications are re-estimated by IV, the results are very similar to those obtained by OLS: the distance to headquarters has a positive impact on dismissals both for firms with headquarters located in low-generosity and high-generosity départements, but the effect is

${ }^{52}$ Catholicism is by far the most important religion in France, with $64 \%$ of French people reporting to be Catholic in the second half of the 2000s.

${ }^{53}$ Data on religiosity have been provided by IFOP (Le Catholicisme en France en 2010). All other controls come from the French Statistical Institute (INSEE).

${ }^{54}$ This is except for unemployment, which is measured at the level of the employment area of the headquarters.

${ }^{55}$ Given that our generosity variable is not as skewed as visibility, it may be less legitimate to dichotomize it into high and low generosity on the basis of a cut-off point at the third quartile of the distribution. When we re-estimate eq. (8) using generosity as a continuous variable using our most complete specification, the results are qualitatively similar to those displayed in table 4 , col. 2 . The point estimate on the interaction between distance to headquarters and generosity is -13.60 ( $\mathrm{SE}=$ 6.46), which is significant at the $5 \%$ level. This suggests that the distance-dismissal relationship gets stronger when generosity at headquarters is lower. 
larger when headquarters are located in low-generosity départements than in high-generosity départements (see table 4, cols. 3 and 4).

Overall, our results are consistent with an interpretation of the effect of distance as reflecting local social pressure at headquarters: in areas where the local community is selfish, people care about dismissals to the extent that they take place close by and threaten them directly. As a consequence, they put pressure on CEOs to shift dismissals away from local areas near the headquarters. In more altruistic communities, this effect is significantly smaller. To make sure that what matters is generosity at headquarters rather than in the community where the plant is located, we run the same type of test as for visibility. We re-estimate equation (8) including an interaction between distance to headquarters and a dummy variable indicating low generosity in the département of the plant. If social pressure in the local community of the plant mattered, it should counterbalance the impact of social pressure at headquarters, so the interaction between distance to headquarters and low generosity at the plant should have a negative and significant impact on dismissals. Here again, the point estimate on the distance $\times$ lowgenerosity-at-plant interaction turns out to be almost 0 (0.006 with SE $=0.021$ ). Moreover, controlling for this interaction does not modify the estimated impact of generosity at headquarters on the distance-dismissal relationship. ${ }^{56}$ These results confirm that CEOs are influenced by social pressure in their local environment when deciding about dismissals, whereas they do not seem to be affected by social pressure arising from more remote local communities.

Such evidence is confirmed when running a placebo test similar to that used for visibility. We first define as placebo headquarters the largest establishments of the firm located in the least generous département where the firm is present (excluding the département of the true headquarters). When estimating equation (8) using these placebo headquarters, we find no significant impact on dismissals of either distance to the placebo headquarters (see appendix table A8, col. 1) or of distance interacted with generosity at the placebo headquarters (see col. 2 of the table). Results are similar if we choose as placebo headquarters a secondary establishment randomly drawn from all the establishments of the firm, excluding those located in the département of the true headquarters (see table A8, cols. 3 and 4). As in the case of visibility, these findings suggest that what matters for dismissals is indeed generosity at headquarters rather than in other départements.

${ }^{56}$ Point estimates comparable to those provided in table 4, col. 2, are obtained by defining the interaction between distance to headquarters and low generosity at plant in deviation from sample mean. The point estimate on the interaction between distance to headquarters and low (high) generosity at headquarters is $0.088(0.036)$ with $\mathrm{SE}=0.026(\mathrm{SE}=0.013)$. 
One could worry that charity giving might capture not only generosity but also some dimension of social capital. To address this problem, we consider an alternative measure of generosity based on the differential turnout rates at the national versus local elections. More specifically, we proxy generosity with the difference between the département-level turnout rates (in percentage of registered voters) at the first round of the 2002 presidential election and the first round of the 2001 municipal elections, excluding towns with a population below 9,000 inhabitants. ${ }^{57}$ The idea underlying this measure is that less selfish (more generous) individuals will be relatively more concerned by national stakes as compared to only local ones, so their relative participation to national elections (as compared to local ones) will be higher.

As above, we classify headquarters as located in high-generosity départements when the latter belong to the upper $25 \%$ of the distribution of differences in turnout rates at presidential and municipal elections. Symmetrically, headquarters are considered to be located in low-generosity départements when the latter belong to the bottom $75 \%$ of the distribution. Let us stress that this measure of generosity does not capture social capital, since it is based on the difference between two indicators (namely, turnout rates) that are likely to be influenced in similar ways by individuals' involvement in collective issues. When regressing dismissal rates on distance to headquarters interacted with this new measure of high and low generosity at headquarters, our findings are similar to those obtained with charity (see appendix table A9, cols. 1 and 2). The impact of distance on dismissals is positive and significant only for firms whose headquarters are located in a local labor market characterized by low generosity. For firms with headquarters located in areas with a high turnout rate at presidential (as compared to municipal) elections, the impact of distance on dismissals is even negative, although statistically insignificant at conventional levels. ${ }^{58}$ These results confirm that social pressure is indeed a key factor in accounting for the distance-dismissal relationship: wherever people are less generous, they put more pressure on CEOs to fire people far away rather than closer to headquarters, whereas when local communities are more altruistic this effect is much smaller.

Finally, we interact firm visibility close to headquarters with the generosity of the local community. If social pressure is an important determinant of dismissals, the positive impact of distance should be the highest for firms with a large share of employment in the local labor market of their head-

${ }^{57}$ The data on turnout rates are provided by the French Ministry of Interior, which does not publish, however, turnout rates for smaller municipalities.

58 These results are virtually unchanged if generosity is defined as a continuous variable, i.e., as the raw difference between turnout rates at the presidential and municipal elections. When re-estimating the specification of table A9, col. 2, we find that the point estimate on the interaction between distance to headquarters and generosity at headquarters is -0.0091 (with $\mathrm{SE}=0.0056$ ). 
quarters and whose headquarters are located in a more selfish community (see eq. [9]). As shown in table 5, this implication is borne out by our estimates. When our model is estimated by OLS (cols. 1 and 2), we find that, whenever high visibility combines with low generosity, the effect on dismissals of increasing distance by 100 kilometers is largest $(0.16$ percentage points) and significantly higher than for any other combination of visibility and generosity. When using IV estimates, the differences in coefficients are less precisely estimated, but the point estimate on distance interacted with low generosity and high visibility is the largest and the only significant one. We interpret these results as indicating that social pressure arising from the local community is a key factor explaining why dismissals are fewer at shorter distance from a firm's headquarters.

\section{Discussion of Alternative Explanations}

Aside from local social pressure at headquarters, there are other candidate explanations of the positive relationship between distance and dismissals. We discuss them in turn and show that none of them can account for all our findings.

\section{A. Public Subsidies}

One reason for lower dismissal rates in establishments located closer to headquarters could be the availability of public subsidies. In France, most local subsidies to economic activity are granted by regional authorities to firms rather than establishments, which are not profit centers. Subsidies may be granted under local social pressure, which would be consistent with our explanation. However, they can also be induced by some form of corruption if politicians exchange these subsidies for financial support from firms for their electoral campaigns. If subsidies reduce the probability of firm downsizing, this could account for our findings. To disentangle local social pressure from the effect of public subsidies, we re-estimate our empirical models using only the subsample of establishments located outside the region of the headquarters. ${ }^{59}$ By so doing, we exclude the main catchment areas of local politicians. We confirm on this subsample that the effect of distance on dismissals is larger for firms with high visibility and headquarters located in low-generosity areas than for any other type of firms and local communities. ${ }^{60}$ Since our key effects do not disappear outside the region of the headquarters, we conclude that the political use of public subsidies cannot be the only mechanism at play.

${ }^{59}$ Each French region encompasses several départements and employment areas (see Sec. IV).

${ }^{60}$ The point estimate on Distance $\times$ Low generosity $\times$ High visibility is 0.194 $(\mathrm{SE}=0.076)$. It is larger than any point estimate on any other interaction, and the difference with the latter is always significant at least at the $6 \%$ level. 


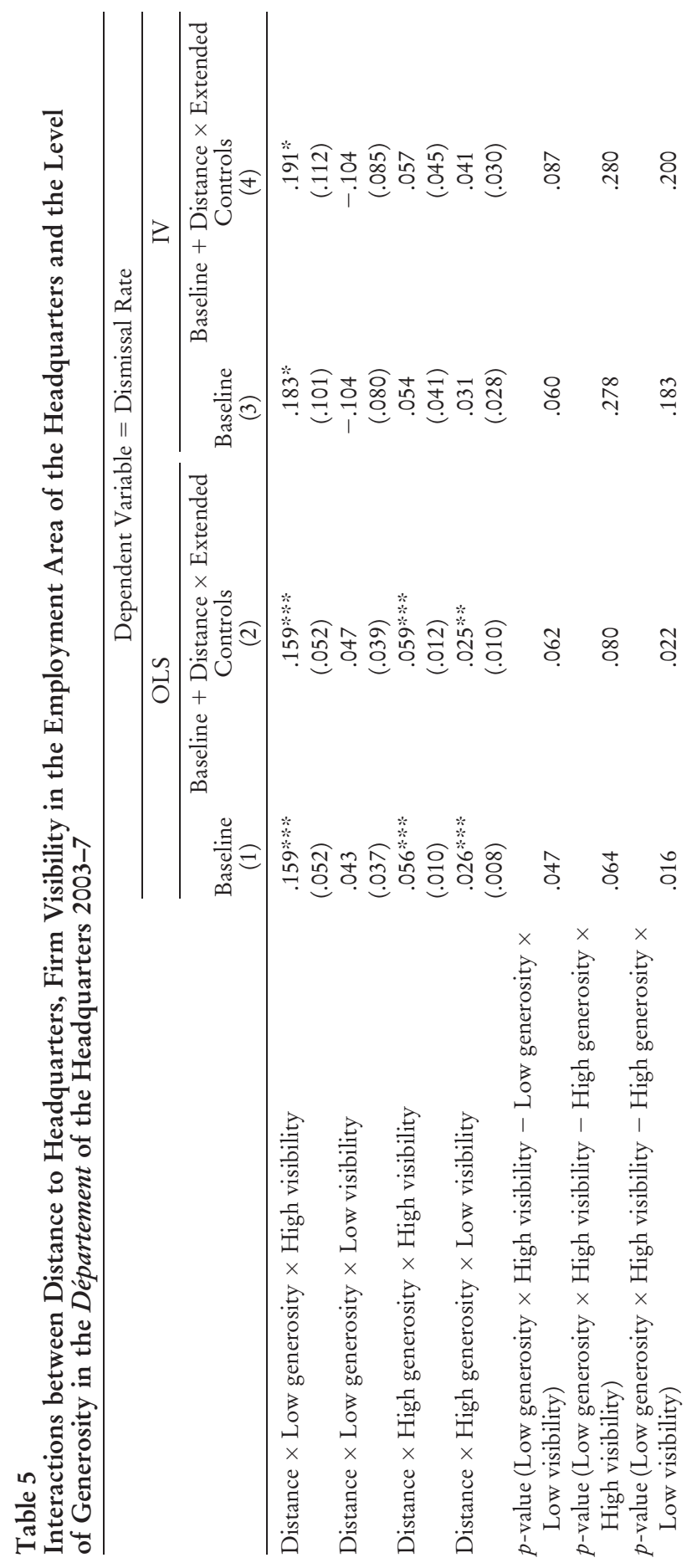




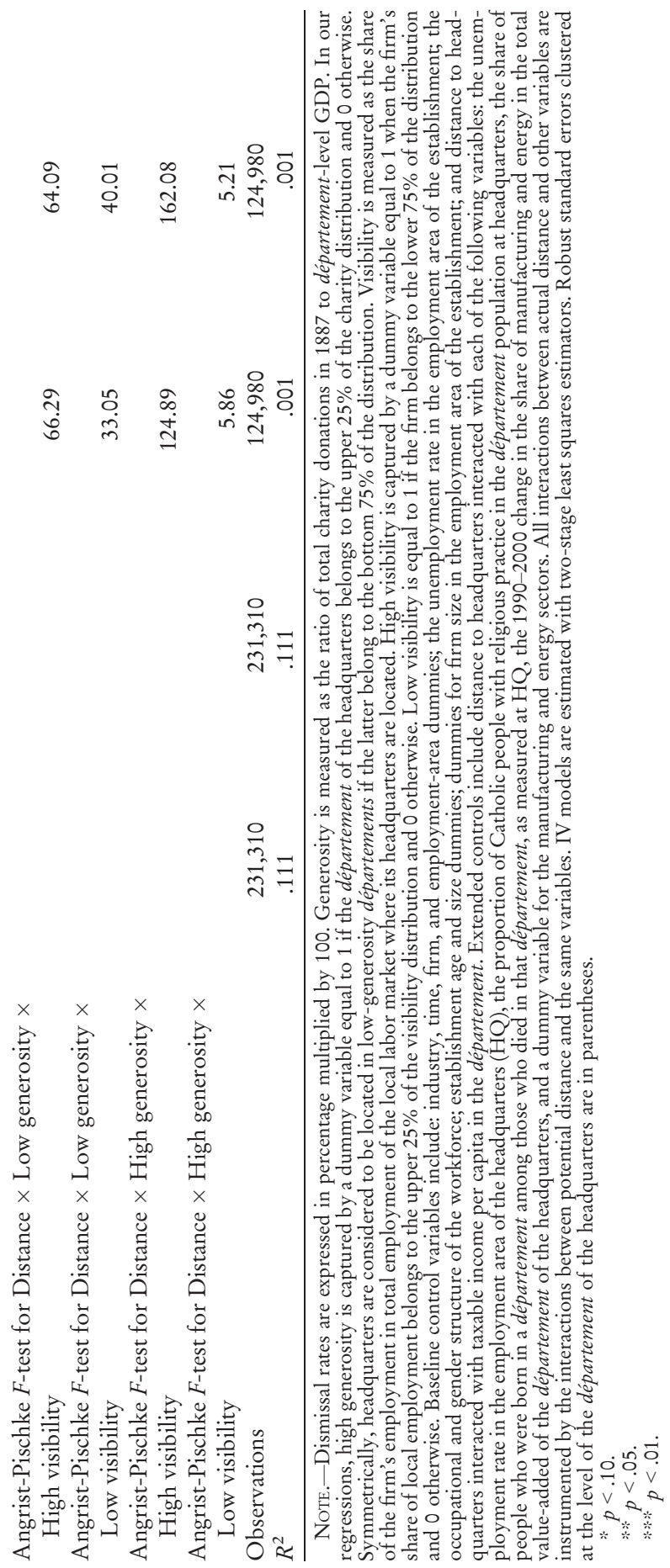




\section{B. Monitoring Costs and Asymmetric Information}

If establishments located far away from headquarters have higher monitoring costs or suffer from asymmetric information, this may negatively affect their performance and therefore increase dismissals. Yet none of these distance-related costs can explain why the impact of distance to headquarters on dismissals is found to increase with the visibility of the firm in the local community of its headquarters, except if highly visible firms are more concentrated close to headquarters and monitoring costs decrease with concentration or if manufacturing firms are more visible and have higher monitoring costs. However, the impact of distance on dismissals increases with visibility even after controlling both for the interaction between distance and firm concentration in the employment area of the headquarters and for the interaction between distance and a dummy for the manufacturing and energy sector. In addition, asymmetric information and monitoring costs cannot explain why the distance-dismissal relationship is steeper whenever the local community at headquarters is more selfish. We therefore rule out that monitoring costs and/or asymmetric information are the only driving factor behind the relationship we have uncovered between distance and dismissals.

\section{Managerial Entrenchment}

Fewer dismissals at short distances could also be due to within-firm social pressure if entrenched managers refrain from firing employees with whom they interact on a regular basis and if interactions are more frequent at short distances. In this case, however, the distance effect should not vary with the firm's visibility at headquarters, except if entrenchment increases with firm size, given that the latter is likely correlated with visibility. However, the finding that the impact of distance on dismissals is stronger when firms are highly visible at headquarters is robust to controlling for the interaction between distance to headquarters and overall firm size in France. ${ }^{61}$

\section{Sorting of Workers and/or Managers}

Good workers may self-select into establishments close to headquarters because career prospects are better. For the same reason, good managers may wish to locate close to headquarters, while bad ones may be forced to stay further away. If good workers are less likely to be dismissed and/ or good managers are better at making their establishments successful-

${ }^{61}$ Re-estimating the specification in table 3, col. 1, and controlling in addition for distance to headquarters interacted with overall firm size in France leaves our results essentially unchanged: the point estimates on Distance $\times$ Low visibility (Distance $\times$ High visibility) are $0.035(0.096)$ with $\mathrm{SE}=0.012(\mathrm{SE}=0.025)$. 
thereby making dismissals unnecessary - this could account for the distancedismissal relationship. In addition, this effect is likely to vary with firm visibility at headquarters if within-firm career prospects are better when firms are larger. However, this cannot be the only determinant, since we show that our results are robust to conditioning on firm size in the employment area of the headquarters interacted with distance.

Good workers and managers may also self-select where the firm is more visible if they expect to have better external job opportunities when coming from a firm that is one of the main actors in its local environment. If this were a key explanation, however, workers should self-select not only in establishments close to headquarters but also in all establishments located in any other area where the firm is highly visible. This would, in turn, generate a positive relationship between dismissals and the distance to any location where the firm is highly visible. The results of our placebo tests indicate that this is not the case: what matters for dismissals is visibility at headquarters, while visibility in other employment areas turns out to have no significant effect. Moreover, none of these sorting mechanisms can explain why the effect of distance varies with the degree of generosity of the local community where the headquarters are located.

\section{E. Place Attachment}

The literature in environmental psychology suggests that individuals are attached to their place of origin. Building on this argument, Yonker (2013) suggests that dismissals may be less numerous close to the CEO's place of origin. Moreover, Yonker (2017) provides evidence that, even in the United States, CEOs tend to be hired locally. If this is the case, dismissals should be less frequent close to headquarters where CEOs live and may come from. However, this effect should not vary with firm visibility. If anything, it should go in the opposite direction: smaller firms are indeed more likely to have CEOs with local origin, so the relationship between distance and dismissals should be stronger where firms are less visible.

\section{F. Altruistic Attitudes of CEOs Independent of Social Pressure}

Socially concerned CEOs are aware that the negative social consequences of high dismissal rates are likely to be stronger wherever their firm represents a larger share of local employment. This concern may explain why they refrain from firing workers in the employment area of the headquarters when their company is highly visible. CEOs' attitudes and concerns do not explain, however, why the relationship between distance and dismissals varies with the generosity of the local community of the headquarters. Moreover, dismissals should be lower wherever the firm accounts for a large proportion of local employment, not just at headquarters, which is not supported by the results of our placebo test. 


\section{G. All the Above Explanations Taken Together}

We have shown that, taken separately, the alternative mechanisms considered in this section cannot account for the different facets of the relationship between distance and dismissals uncovered by our empirical analysis. Can they do so jointly? The answer to this question turns out to be negative, since none of these explanations can account for the fact that, even outside the region of the headquarters, the relationship between distance and dismissals is stronger for high-visibility firms whose headquarters are located in areas with more selfish local communities.

\section{Conclusion}

In this paper, we have shown that firms are sensitive to social pressure in the local environment where their headquarters are located, which induces them to refrain from dismissing at short distance from headquarters. Using French linked employer-employee data, we have shown that dismissal rates increase with the distance of secondary establishments to headquarters. This result holds even after controlling for the endogeneity of the distance to headquarters. We have also found that the positive effect of distance on dismissals increases with the firm's share of total employment in the local labor market of its headquarters. The estimated effect of distance on dismissals is also stronger the greater the degree of selfishness of the local community at headquarters. This suggests that wherever firms are more visible at headquarters or the community of the headquarters is more selfish, firms are more reluctant to fire closely located workers. This is consistent with the idea that $\mathrm{CEO}$ s are under local social pressure in their community to reduce as much as possible dismissals in their area. We have shown that these results are explained by an adjustment cost model of employment decisions made by CEOs under the threat of local social sanctions. By contrast, they cannot be entirely accounted for by alternative explanations of the positive relationship between distance and dismissals proposed in the literature.

Our findings suggest that social pressure exerted by the community of their headquarters has an important impact on the way firms accommodate negative shocks, particularly on their dismissal policy. The natural question to ask is, then, who exactly is affected by social pressure? Is it the owner of the firm or the CEO? If it is the CEO, and the CEO is not one of the main shareholders of the firm, his/her decisions may not be profit-maximizing. In this case, the relationship between distance and dismissals is likely to be stronger the weaker the firm's governance. While our data do not contain information on firm governance, we believe that understanding how governance affects employment decisions when the CEO is exposed to local social pressure is a challenging avenue for further research. 
By focusing on firms registered in France, our paper has nothing to say on the effects of social pressure on the employment adjustment of multinational companies. Do multinational firms also react to local social pressure in their home country? Do they tend to shift the burden of painful employment adjustments onto subsidiaries located in foreign countries? This question is of particular relevance given the increasing level of globalization of advanced economies. Investigating these effects on an international scale would require getting access to appropriate plant-level data for several countries. While we are unaware of the existence of such data, we believe that investigating this issue would be of major importance to understand how the presence of multinational companies may affect the resilience of countries to negative economic shocks.

\section{Appendix}

\section{A1. Derivation of the Impact of Visibility on the Effect of Distance to Headquarters on Dismissals}

The derivative of $D_{i}^{*}$ with respect to $\alpha$ yields:

$$
\frac{\partial D_{i}^{*}}{\partial \alpha}=\left(\frac{\lambda_{G}}{f_{\mathrm{NN}}\left(\theta_{G}, N_{i}^{G}\right)}+\frac{r+\lambda_{B}}{f_{\mathrm{NN}}\left(\theta_{B}, N_{i}^{B}\right)}\right) \gamma_{i} .
$$

The effect of visibility on the relationship between distance and dismissals is given by the sign of the following expression:

$$
\begin{aligned}
\frac{\partial\left(D_{2}^{*}-D_{1}^{*}\right)}{\partial \alpha} & =\left(\frac{\lambda_{G}}{f_{\mathrm{NN}}\left(\theta_{G}, N_{2}^{G}\right)}+\frac{r+\lambda_{B}}{f_{\mathrm{NN}}\left(\theta_{B}, N_{2}^{B}\right)}\right) \gamma_{2} \\
& -\left(\frac{\lambda_{G}}{f_{\mathrm{NN}}\left(\theta_{G}, N_{1}^{G}\right)}+\frac{r+\lambda_{B}}{f_{\mathrm{NN}}\left(\theta_{B}, N_{1}^{B}\right)}\right) \gamma_{1} .
\end{aligned}
$$

Taking into account that $f_{\mathrm{NN}}<0$, the right-hand side of (A2) is positive, if and only if

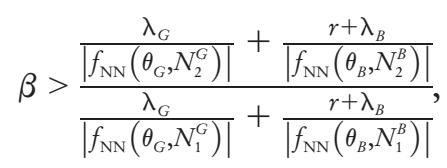

where $\beta=\gamma_{1} / \gamma_{2}$ is the degree of selfishness and $|x|$ denotes the absolute value of $x$. Since $N_{2}^{B}<N_{1}^{B}$ and $f_{\mathrm{NNN}} \geq 0,\left|f_{N N}\left(\theta_{B}, N_{2}^{B}\right)\right| \geq\left|f_{N N}\left(\theta_{B}, N_{1}^{B}\right)\right|$, the above inequality holds if 


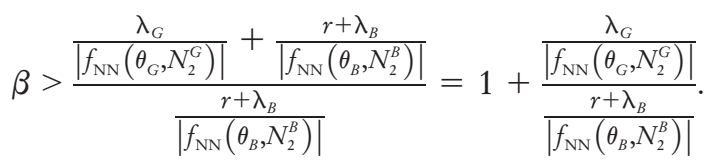

The fact that $f_{\mathrm{NNN}} \geq 0$ implies that $\left|f_{\mathrm{NN}}\left(\theta_{B}, N_{2}^{B}\right)\right| \leq\left|f_{\mathrm{NN}}\left(\theta_{B}, N_{0}^{B}\right)\right|$, where $N_{0}^{B}$ is the value obtained by solving equation (3) for $b_{i}=0$. Similarly, $\left|f_{\mathrm{NN}}\left(\theta_{G}, N_{2}^{G}\right)\right| \geq\left|f_{\mathrm{NN}}\left(\theta_{G}, N_{0}^{G}\right)\right|$, where $N_{0}^{G}$ is the value obtained by solving equation (2) for $b_{i}=0$. Therefore, a sufficient condition for (A4) to hold is that

$$
\beta>1+\frac{\frac{\lambda_{G}}{f_{\mathrm{NN}}\left(\theta_{G}, N_{0}^{G}\right)}}{\frac{r+\lambda_{B}}{f_{\mathrm{NN}}\left(\theta_{B}, N_{0}^{B}\right)}} .
$$

This implies that a sufficient condition for (A2) to be positive is that the degree of selfishness, $\beta=\gamma_{1} / \gamma_{2}$, be large enough.

\section{A2. Derivation of the Effect of Selfishness on the Impact of Visibility on the Distance-Dismissal Relationship}

Since, conditional on $\gamma_{1}, \beta$ does not affect $D_{1}^{*}$, it is straightforward that

$$
\frac{\partial\left(D_{2}^{*}-D_{1}^{*}\right)}{\partial \beta}=\frac{\partial D_{2}^{*}}{\partial \beta} .
$$

This implies that $\partial^{2}\left(D_{2}^{*}-D_{1}^{*}\right) / \partial \alpha \partial \beta=\partial^{2} D_{2}^{*} / \partial \alpha \partial \beta$. Taking the first derivative of the right-hand side of equation (A1) with respect to $\beta$ for $i=2$, and taking into account that $\gamma_{2}=\gamma_{1} / \beta$ yields

$$
\begin{aligned}
\frac{\partial^{2} D_{2}^{*}}{\partial \beta \partial \alpha}= & -\frac{\gamma_{1}}{\beta^{2}}\left(\frac{\lambda_{G}}{f_{\mathrm{NN}}\left(\theta_{G}, N_{2}^{G}\right)}+\frac{r+\lambda_{B}}{f_{\mathrm{NN}}\left(\theta_{B}, N_{2}^{B}\right)}\right) \\
& +\frac{\gamma_{1}}{\beta}\left(\frac{\lambda_{G} f_{\mathrm{NNN}}\left(\theta_{G}, N_{2}^{G}\right)}{\left[f_{\mathrm{NN}}\left(\theta_{G}, N_{2}^{G}\right)\right]^{2}} \frac{\partial N_{2}^{G}}{\partial \beta}+\frac{\left(r+\lambda_{B}\right) f_{\mathrm{NNN}}\left(\theta_{B}, N_{2}^{B}\right)}{\left[f_{\mathrm{NN}}\left(\theta_{B}, N_{2}^{B}\right)\right]^{2}} \frac{\partial N_{2}^{B}}{\partial \beta}\right) .
\end{aligned}
$$

Using $\partial N_{2}^{G} / \partial \beta=-\lambda_{G} \alpha \gamma_{1} / \beta^{2}$ and $\partial N_{2}^{B} / \partial \beta=\left(r+\lambda_{B}\right) \alpha \gamma_{1} / \beta^{2}$, we have

$$
\begin{aligned}
\frac{\partial^{2} D_{2}^{*}}{\partial \beta \partial \alpha}= & -\frac{\gamma_{1} \lambda_{G}}{\beta^{2} f_{\mathrm{NN}}\left(\theta_{G}, N_{2}^{G}\right)}\left(1-\frac{\lambda_{G} \alpha \gamma_{1} f_{\mathrm{NNN}}\left(\theta_{G}, N_{2}^{G}\right)}{\beta\left[f_{\mathrm{NN}}\left(\theta_{G}, N_{2}^{G}\right)\right]^{2}}\right) \\
& -\frac{\gamma_{1}\left(r+\lambda_{B}\right)}{\beta^{2} f_{\mathrm{NN}}\left(\theta_{B}, N_{2}^{B}\right)}\left(1+\frac{\left(r+\lambda_{B}\right) \alpha \gamma_{1} f_{\mathrm{NNN}}\left(\theta_{B}, N_{2}^{B}\right)}{\beta\left[f_{\mathrm{NN}}\left(\theta_{B}, N_{2}^{B}\right)\right]^{2}}\right) .
\end{aligned}
$$

Given that $f_{N N}<0, f_{N N N} \geq 0$, and the last term in parentheses is positive, this expression is positive if $\beta$ is sufficiently large, so $\lambda_{G} \alpha \gamma_{1} f_{\mathrm{NNN}}\left(\theta_{G}, N_{2}^{G}\right) /$ $\beta\left[f_{\mathrm{NN}}\left(\theta_{G}, N_{2}^{G}\right)\right]^{2} \leq 1$. Obviously, this represents only a sufficient condition. 


\section{A3. Figures and Tables}

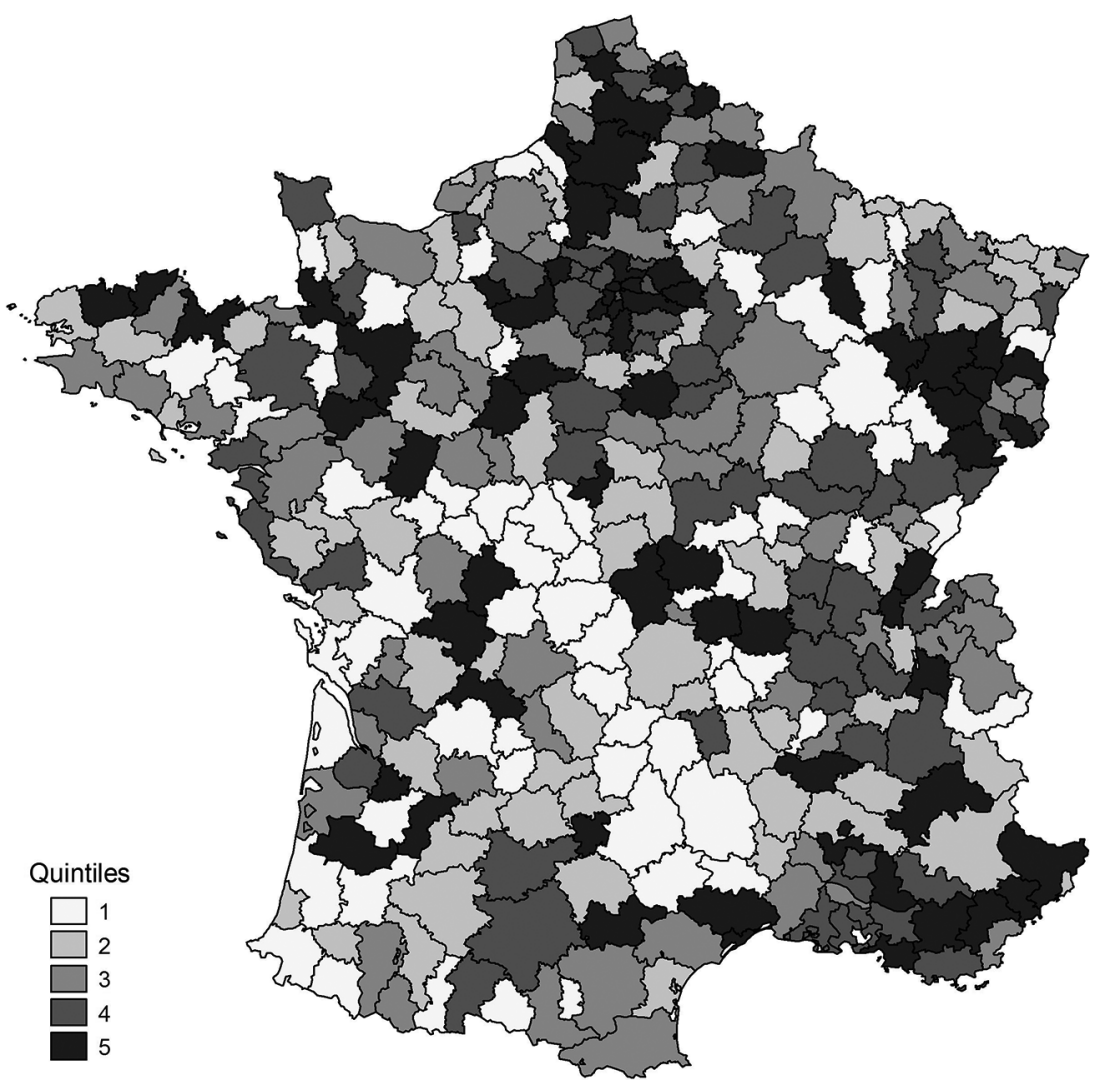

Fig. A1.-Distribution of dismissal rates in French employment areas, by quintile of the distribution. Main sample. Quintiles are ordered from the lowest to the highest. A color version of this figure is available online. 


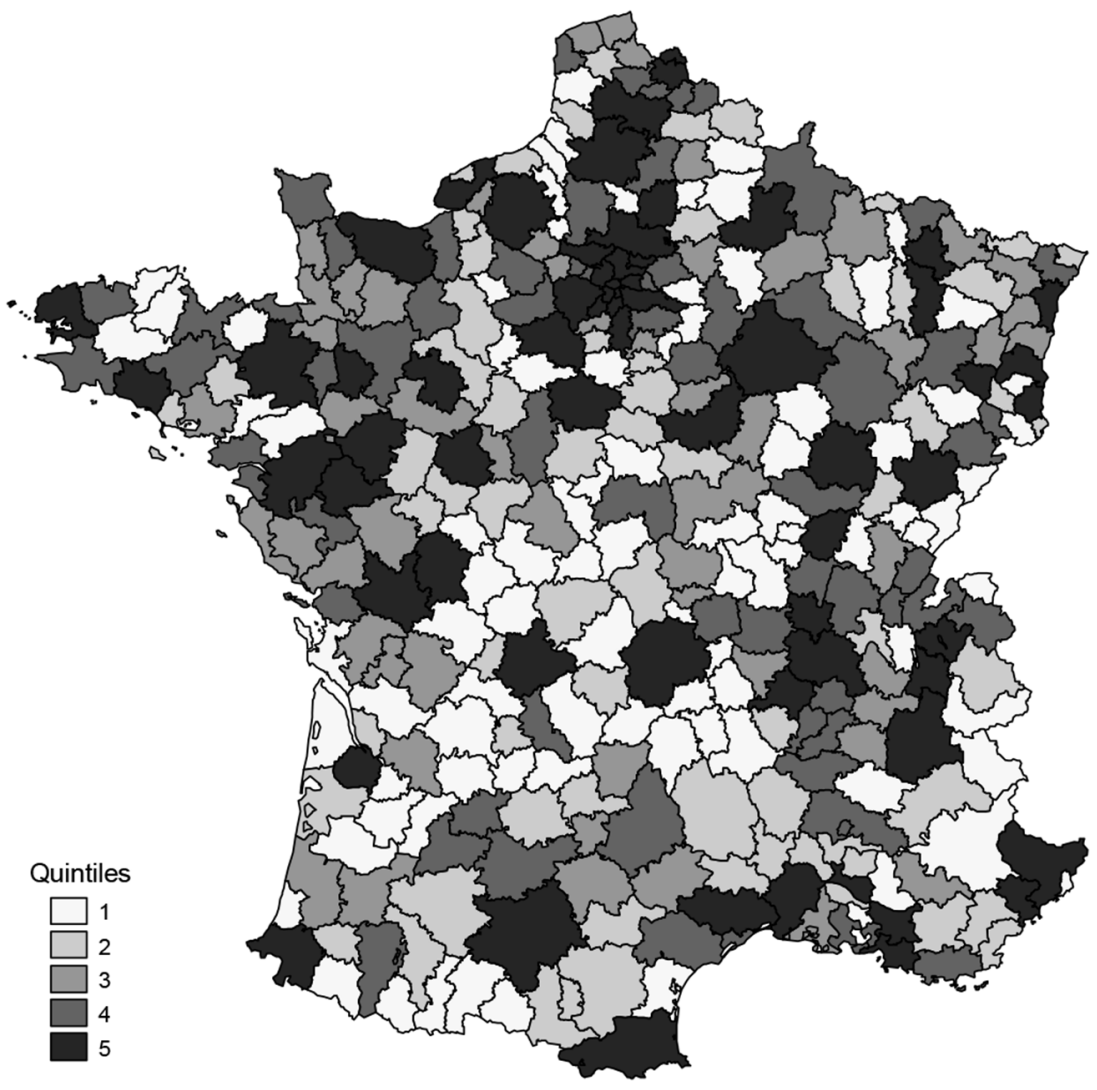

FIG. A2.- Number of headquarters in French employment areas, by quintile of the distribution. Main sample. Quintiles are ordered from the lowest to the highest. A color version of this figure is available online. 


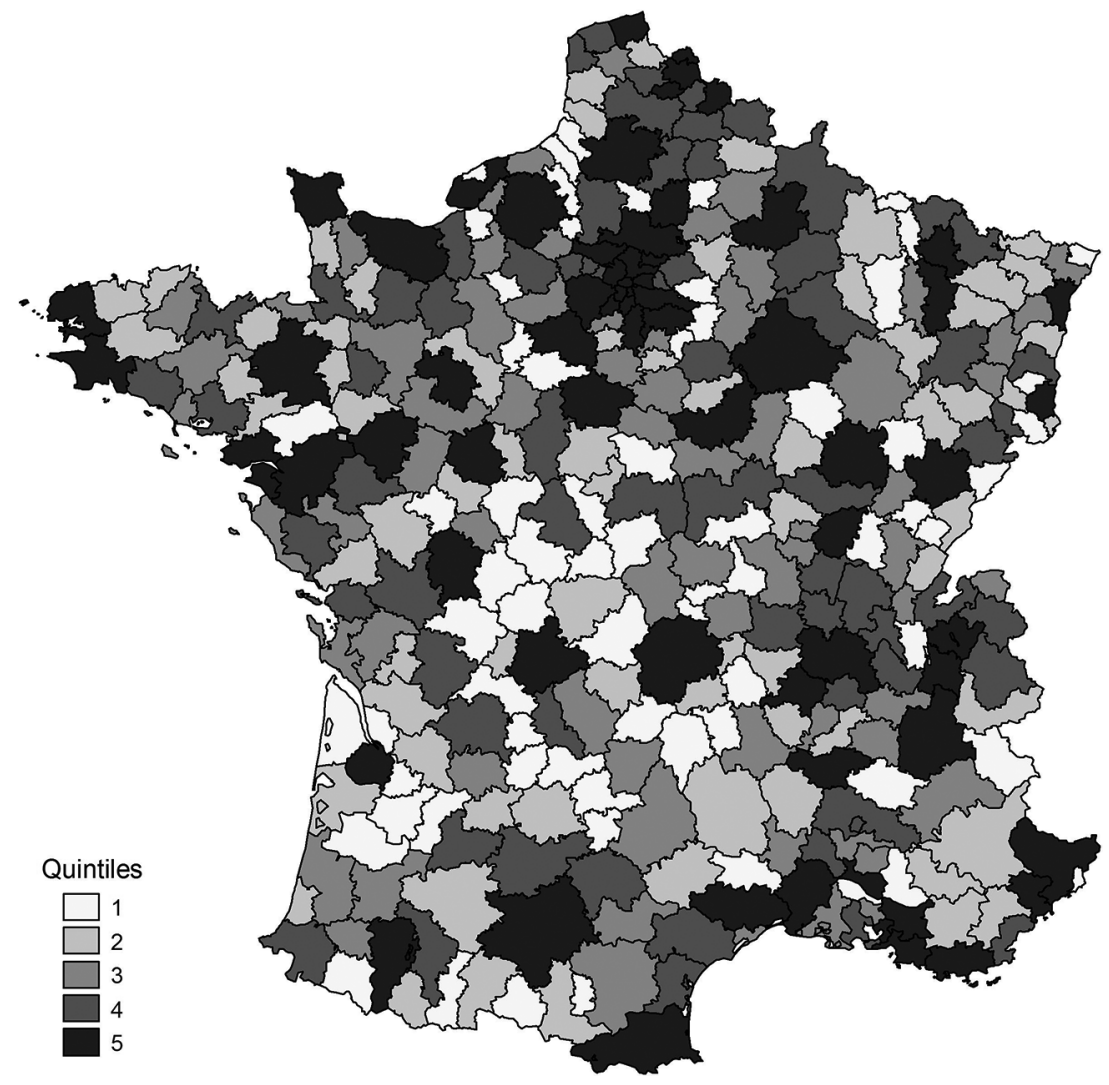

FIG. A3.-Number of secondary establishments in French employment areas, by quintile of the distribution. Main sample. Quintiles are ordered from the lowest to the highest. A color version of this figure is available online. 


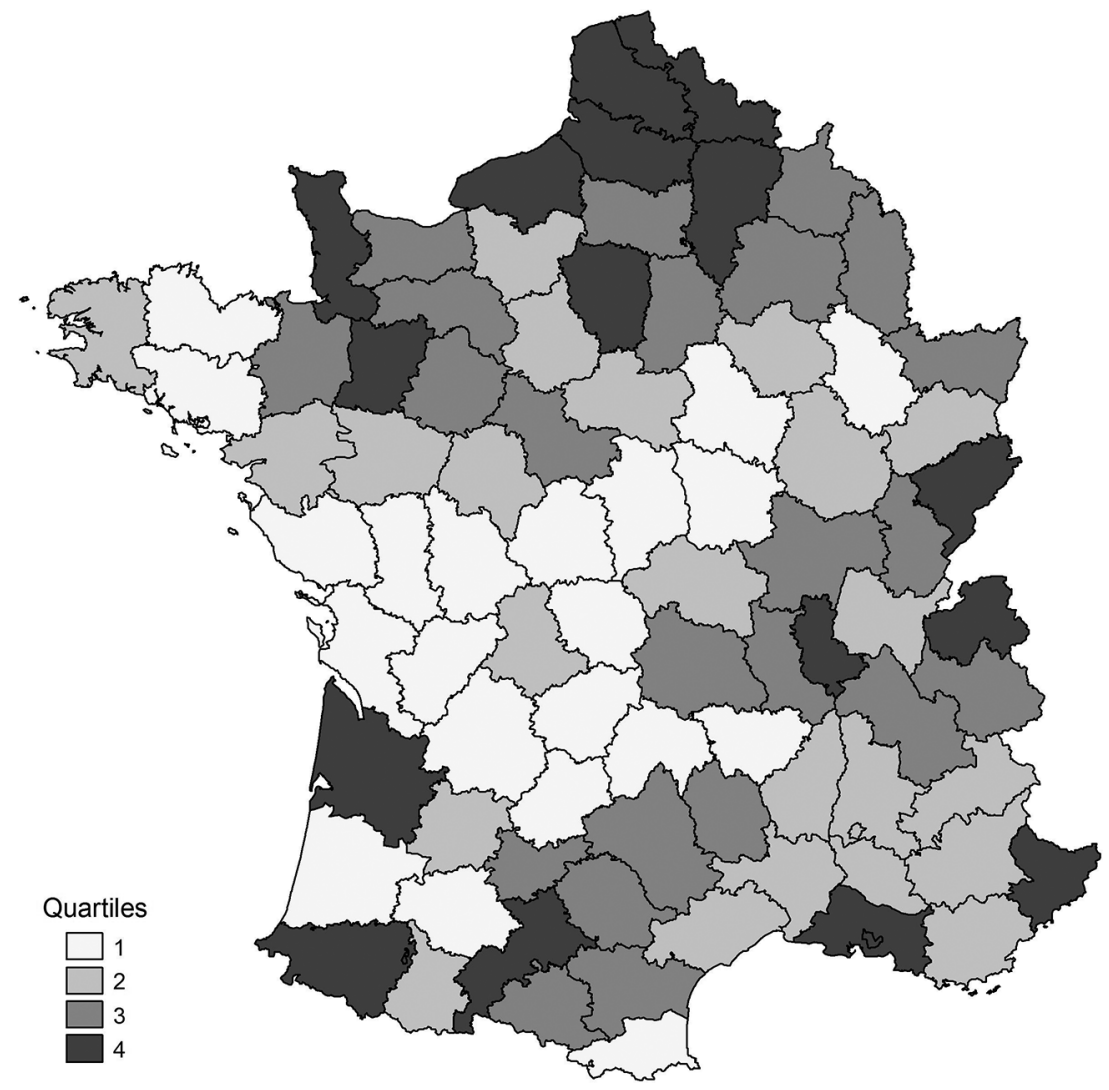

FIG. A4.-Ratio of charity giving to gross domestic product (GDP) in French Départements, by quartile of the distribution. Département-level charity giving is measured in 1887; département-level GDP is measured in 1864. Quartiles are ordered from the lowest to the highest. Départements with missing data are not shown on the map. A color version of this figure is available online. 
Table A1

Descriptive Statistics (Main Sample)

\begin{tabular}{|c|c|c|c|c|c|}
\hline Variable & Mean & SD & Variable & Mean & SD \\
\hline \multicolumn{6}{|l|}{$\begin{array}{l}\text { Quarterly worker flow rates } \\
\text { (\% of plant employment): }\end{array}$} \\
\hline Dismissals: & .97 & 4.59 & $\begin{array}{c}\text { Manufacturing and } \\
\text { energy }(\%)\end{array}$ & 26.19 & 43.97 \\
\hline Manufacturing and energy & .86 & 6.14 & $\begin{array}{c}\text { Construction and } \\
\text { services (\%) }\end{array}$ & 73.81 & 43.97 \\
\hline Construction and services & 1.02 & 3.90 & & & \\
\hline End of fixed-term contract & 5.73 & 52.55 & $\begin{array}{l}\text { Local unemployment } \\
\text { rate }(\%)\end{array}$ & 8.41 & 1.96 \\
\hline End-of-trial period & .55 & 2.55 & & & \\
\hline Retirement & .33 & 1.41 & Establishment size & 136.43 & 299.13 \\
\hline Quits & 1.78 & 4.19 & & & \\
\hline \multirow[t]{2}{*}{ Total separations } & 11.54 & 55.12 & $\begin{array}{l}\text { Establishment age (by } \\
\text { class): }\end{array}$ & & \\
\hline & & & 2 years & .10 & .30 \\
\hline Structure of the workforce & & & 3 years & & \\
\hline (\% of plant employment): & & & & .10 & .30 \\
\hline Managers & 14.78 & 20.27 & 4 years & .10 & .30 \\
\hline Technicians and supervisors & 24.81 & 21.41 & 5 years or more & .63 & .48 \\
\hline Clerks & 27.09 & 31.15 & & & \\
\hline Blue-collar workers & 33.16 & 32.72 & Firm-level variables: & & \\
\hline Board members & .15 & 1.14 & Firm size & 906.8 & $4,288.12$ \\
\hline Women & 37.48 & 25.73 & Firm age (years) & 23.39 & 14.89 \\
\hline
\end{tabular}

Table A2

Number of Secondary Establishments per Firm: Firms in the Main Sample

\begin{tabular}{lcc}
\hline & $\begin{array}{c}\text { Establishments in the } \\
\text { Main Sample } \\
(1)\end{array}$ & $\begin{array}{c}\text { Establishments in Mainland } \\
\text { France } \\
(2)\end{array}$ \\
\hline 1st quartile & 2 & 3 \\
Median & 2 & 6 \\
Mean & 5.88 & 23.89 \\
3rd quartile & 5 & 14 \\
Maximum & 863 & 3,163 \\
\hline
\end{tabular}

NOTE.-Column 1 only includes establishments belonging to the regression sample. Column 2 includes all establishments of the firms in the regression sample, whether or not these establishments belong to that sample.

Table A3

Distance to Headquarters: Main Sample

\begin{tabular}{lrr}
\hline Variable & Mean & \multicolumn{1}{c}{ SD } \\
\hline Distance to headquarters (kilometers) & 247.98 & 216.31 \\
Distance to closest establishment (kilometers) & 43.58 & 97.64 \\
Distance to second closest establishment (kilometers) & 72.69 & 129.00 \\
Distance to farthest establishment (kilometers) & 510.76 & 261.60 \\
\hline
\end{tabular}


Table A4

Visibility and Generosity at Headquarters

\begin{tabular}{lr}
\hline Variable & Statistic \\
\hline Firm's share of total employment in headquarter's employment area (\%): & \\
1st quartile & .026 \\
Median & .090 \\
Mean & .330 \\
3rd quartile & .299 \\
Maximum & 27.288 \\
Ratio of total charity donations to GDP (\%) in headquarter's département: & \\
Minimum & .012 \\
1st quartile & .093 \\
Median & .129 \\
Mean & .152 \\
3rd quartile & .184 \\
Maximum & .658 \\
\hline
\end{tabular}




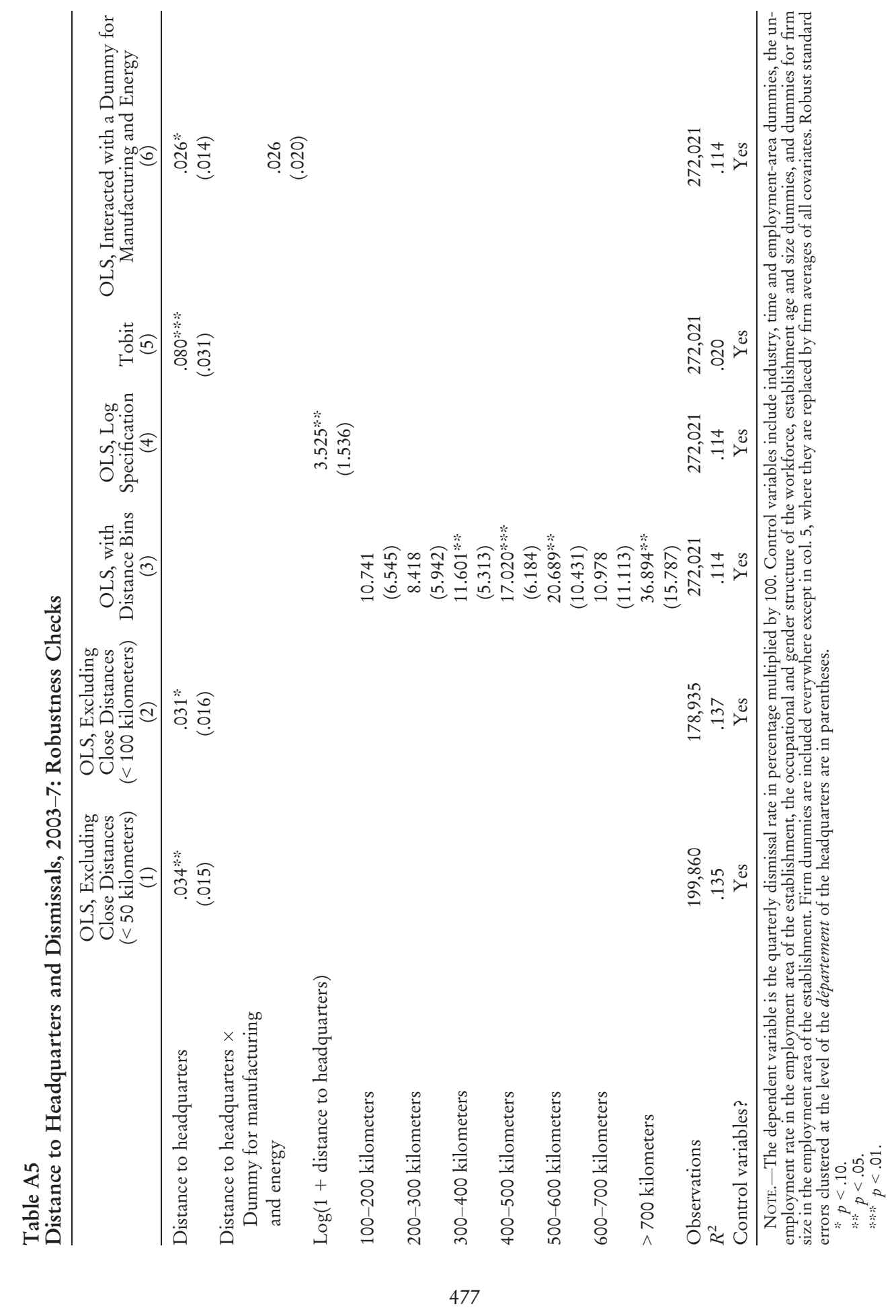


Table A6

Distance to Headquarters and Other Types of Worker Separations, 2003-7

\begin{tabular}{lcccc}
\hline & \multicolumn{4}{c}{ Dependent Variable } \\
\cline { 2 - 5 } & $\begin{array}{c}\text { Quits } \\
(1)\end{array}$ & $\begin{array}{c}\text { End of Trial Period } \\
(2)\end{array}$ & $\begin{array}{c}\text { Retirement } \\
(3)\end{array}$ & $\begin{array}{c}\text { End of Fixed-Term } \\
\text { Contracts } \\
(4)\end{array}$ \\
\hline $\begin{array}{l}\text { Distance to } \\
\text { headquarters }\end{array}$ & .014 & .010 & .002 & -.047 \\
Observations & $(.014)$ & $(.009)$ & $(.004)$ & $(.096)$ \\
$R^{2}$ & 272,020 & 272,024 & 272,024 & 271,802 \\
Control & .308 & .341 & .076 & .467 \\
$\quad$ variables? & Yes & Yes & Yes & Yes \\
\hline
\end{tabular}

NoTE.- Rates are expressed in percentage multiplied by 100. Control variables include industry, time, firm, and employment-area dummies; the unemployment rate in the employment area of the establishment; the occupational and gender structure of the workforce; establishment age and size dummies; and dummies for firm size in the employment area of the establishment. Robust standard errors clustered at the level of the département of the headquarters are in parentheses.

Table A7

Placebo Tests: Visibility

\begin{tabular}{|c|c|c|c|c|}
\hline & \multicolumn{4}{|c|}{ Dependent Variable $=$ Dismissal Rate } \\
\hline & \multicolumn{2}{|c|}{$\begin{array}{l}\text { Placebo Headquarters = } \\
\text { Largest Plant in the Area } \\
\text { Where the Firm } \\
\text { Is Most Visible }\end{array}$} & \multicolumn{2}{|c|}{$\begin{array}{c}\text { Placebo Headquarters }= \\
\text { Randomly Drawn }\end{array}$} \\
\hline & $(1)$ & $(2)$ & (3) & (4) \\
\hline Distance to placebo headquarters & $\begin{array}{l}.009 \\
(.009)\end{array}$ & & $\begin{array}{r}-.011 \\
(.008)\end{array}$ & \\
\hline Distance $\times$ Low visibility & & $\begin{array}{l}.004 \\
(.013)\end{array}$ & & $\begin{array}{r}-.007 \\
(.009)\end{array}$ \\
\hline Distance $\times$ High visibility & & $\begin{array}{l}.013 \\
(.011)\end{array}$ & & $\begin{array}{l}-.025 \\
(.020)\end{array}$ \\
\hline Observations & 228,405 & 228,405 & 228,405 & 228,405 \\
\hline$R^{2}$ & .106 & .106 & .106 & .106 \\
\hline Control variables? & Yes & Yes & Yes & Yes \\
\hline
\end{tabular}

NOTE.-Plants in the same employment area as the headquarters are excluded from the set where placebo headquarters are drawn from. Dismissal rates are expressed in percentage multiplied by 100 . Visibility is measured as the share of the firm's employment in total employment of the local labor market where its placebo headquarters are located. High visibility is captured by a dummy variable equal to 1 when the firm's share of local employment belongs to the upper $25 \%$ of the visibility distribution and 0 otherwise. Low visibility is equal to 1 if the firm belongs to the lower $75 \%$ of the distribution and 0 otherwise. Control variables include industry, time, firm, and employment-area dummies; the unemployment rate in the employment area of the establishment; the occupational and gender structure of the workforce; establishment age and size dummies and dummies for firm size in the employment area of the establishment. Robust standard errors clustered at the level of the département of the placebo headquarters are in parentheses. 
Table A8

Placebo Tests: Generosity

\begin{tabular}{|c|c|c|c|c|}
\hline & \multicolumn{4}{|c|}{ Dependent Variable $=$ Dismissal Rate } \\
\hline & \multicolumn{2}{|c|}{$\begin{array}{l}\text { Placebo Headquarters = } \\
\text { Largest Plant in the Least } \\
\text { Generous Département }\end{array}$} & \multicolumn{2}{|c|}{$\begin{array}{c}\text { Placebo Headquarters }= \\
\text { Randomly Drawn }\end{array}$} \\
\hline & $(1)$ & $(2)$ & (3) & (4) \\
\hline Distance to placebo headquarters & $\begin{array}{l}.009 \\
(.012)\end{array}$ & & $\begin{array}{c}.001 \\
(.007)\end{array}$ & \\
\hline Distance $\times$ Low generosity & & $\begin{array}{l}.009 \\
(.012)\end{array}$ & & $\begin{array}{l}.000 \\
(.012)\end{array}$ \\
\hline Distance $\times$ High generosity & & $\begin{array}{c}.021 \\
(.025)\end{array}$ & & $\begin{array}{c}.001 \\
(.009)\end{array}$ \\
\hline Observations & 248,645 & 248,645 & 248,645 & 248,645 \\
\hline$R^{2}$ & .105 & .105 & .105 & .105 \\
\hline Control variables? & Yes & Yes & Yes & Yes \\
\hline
\end{tabular}

Note.-Plants in the same département as the headquarters are excluded from the set where placebo headquarters are drawn from. Dismissal rates are expressed in percentage multiplied by 100 . Generosity is measured as the ratio of total charity donations in 1887 to département-level gross domestic product. High generosity is captured by a dummy variable equal to 1 if the département of the placebo HQ belongs to the upper $25 \%$ of the charity distribution and 0 otherwise. Symmetrically, placebo headquarters are considered to be located in low-generosity départements if the latter belong to the bottom $75 \%$ of the distribution. Control variables include industry, time, firm, and employment-area dummies; the unemployment rate in the employment area of the establishment; the occupational and gender structure of the workforce; establishment; age and size dummies; dummies for firm size in the employment area of the establishment; and, in columns 2 and 4 , distance to placebo headquarters interacted with taxable income per capita in the département. Robust standard errors clustered at the level of the département of the placebo headquarters in parentheses.

Table A9

Interactions between Distance to Headquarters and the Level of Generosity (Based on Turnout Rates at National versus Local Elections) in the Département of the Headquarters, 2003-7

\begin{tabular}{|c|c|c|c|c|}
\hline & & Dependent Variabl & $\mathrm{e}=$ Dismi & ssal Rate \\
\hline & $\begin{array}{l}\text { Baseline } \\
\text { (1) }\end{array}$ & $\begin{array}{c}\text { Baseline }+ \text { Dis- } \\
\text { tance } \times \text { Extended } \\
\text { Controls } \\
(2)\end{array}$ & $\begin{array}{l}\text { Baseline } \\
\text { (3) }\end{array}$ & $\begin{array}{c}\text { Baseline }+ \text { Dis- } \\
\text { tance } \times \text { Extended } \\
\text { Controls } \\
(4)\end{array}$ \\
\hline Distance $\times$ Low generosity & $\begin{array}{l}.059 * * * \\
(.016)\end{array}$ & $\begin{array}{l}.061 * * * \% \\
(.016)\end{array}$ & & \\
\hline Distance $\times$ High generosity & $\begin{array}{l}-.021 \\
(.025)\end{array}$ & $\begin{array}{l}-.039 \\
(.029)\end{array}$ & & \\
\hline $\begin{array}{l}\text { Distance } \times \text { Low generosity } \times \\
\text { High visibility }\end{array}$ & & & $\begin{array}{l}.093 * * * \\
(.016)\end{array}$ & $\begin{array}{l}.098 * * * \\
(.016)\end{array}$ \\
\hline $\begin{array}{l}\text { Distance } \times \text { Low generosity } \times \\
\text { Low visibility }\end{array}$ & & & $\begin{array}{l}.054 * * * \\
(.012)\end{array}$ & $\begin{array}{l}.055^{* * * *} \\
(.012)\end{array}$ \\
\hline $\begin{array}{l}\text { Distance } \times \text { High generosity } \times \\
\text { High visibility }\end{array}$ & & & $\begin{array}{l}.025 \\
(.028)\end{array}$ & $\begin{array}{l}.013 \\
(.029)\end{array}$ \\
\hline $\begin{array}{l}\text { Distance } \times \text { High generosity } \times \\
\text { Low visibility }\end{array}$ & & & $\begin{array}{r}-.018 \\
(.025)\end{array}$ & $\begin{array}{l}-.035 \\
(.032)\end{array}$ \\
\hline
\end{tabular}


Table A9 (Continued)

\begin{tabular}{|c|c|c|c|c|}
\hline & \multicolumn{4}{|c|}{ Dependent Variable $=$ Dismissal Rate } \\
\hline & \multicolumn{3}{|c|}{$\begin{array}{l}\text { Baseline }+ \text { Dis- } \\
\text { tance } \times \text { Extended }\end{array}$} & \multirow{2}{*}{$\begin{array}{c}\text { Baseline }+ \text { Dis- } \\
\text { tance } \times \text { Extended } \\
\text { Controls } \\
(4)\end{array}$} \\
\hline & $\begin{array}{l}\text { Baseline } \\
\text { (1) }\end{array}$ & $\begin{array}{l}\text { Controls } \\
\text { (2) }\end{array}$ & $\begin{array}{l}\text { Baseline } \\
\text { (3) }\end{array}$ & \\
\hline \multicolumn{5}{|l|}{$p$-value (High generosity - Low } \\
\hline \multicolumn{5}{|l|}{$\begin{array}{l}p \text {-value (Low generosity } \times \text { High } \\
\text { visibility }- \text { Low generosity } \times\end{array}$} \\
\hline Low visibility) & & & .003 & .001 \\
\hline \multicolumn{5}{|l|}{$\begin{array}{l}p \text {-value (Low generosity } \times \text { High } \\
\text { visibility }- \text { High generosity } \times\end{array}$} \\
\hline High visibility) & & & .054 & .022 \\
\hline \multicolumn{5}{|l|}{$\begin{array}{l}p \text {-value (Low generosity } \times \text { High } \\
\text { visiblity }- \text { High generosity } \times\end{array}$} \\
\hline Low visiblity) & & & .020 & .002 \\
\hline Observations & 271,614 & 271,614 & 238,243 & 238,243 \\
\hline$R^{2}$ & .114 & .114 & .111 & .111 \\
\hline \multicolumn{5}{|c|}{$\begin{array}{l}\text { NOTE.-Dismissal rates are expressed in percentage multiplied by } 100 \text {. Generosity is measured as the dif- } \\
\text { ference between the département-level turnout rates (in percentage of registered voters) at the first round of } \\
\text { the } 2002 \text { presidential election and the first round of the } 2001 \text { municipal elections, excluding towns with } \\
\text { population below } 9,000 \text { inhabitants. High generosity is captured by a dummy variable equal to } 1 \text { if the } \\
\text { département of the headquarters belongs to the upper } 25 \% \text { of this generosity distribution and } 0 \text { otherwise. } \\
\text { Symmetrically, headquarters are considered to be located in low-generosity départements if the latter be- } \\
\text { long to the bottom } 75 \% \text { of the distribution. Visibility is measured as the share of the firm's employment in } \\
\text { total employment in the employment area where its headquarters are located. High visibility is captured by } \\
\text { a dummy variable equal to } 1 \text { when the firm's share of local employment belongs to the upper } 25 \% \text { of the } \\
\text { visibility distribution and } 0 \text { otherwise. Low visibility is equal to } 1 \text { if the firm belongs to the lower } 75 \% \text { of } \\
\text { the distribution and } 0 \text { otherwise. Baseline control variables include industry, time, firm, and employment- } \\
\text { area dummies; the unemployment rate in the employment area of the establishment; the occupational and } \\
\text { gender structure of the workforce; establishment age and size dummies; and dummies for firm size in the } \\
\text { employment area of the establishment. Extended controls include distance to headquarters interacted with } \\
\text { each of the following variables: taxable income per capita in the département of the headquarters, the un- } \\
\text { employment rate in the employment area of the headquarters, the proportion of Catholic people with re- } \\
\text { ligious practice in the département population at the headquarters, the share of people who were born in a } \\
\text { département among those who died in that département as measured at headquarters, the } 1990-2000 \\
\text { change in the share of manufacturing and energy in the total value-added of the département of the head- } \\
\text { quarters, and a dummy variable for the manufacturing and energy sectors. Robust standard errors clustered } \\
\text { at the level of the département of the headquarters are in parentheses. } \\
* \% * \text { p }<.01 \text {. }\end{array}$} \\
\hline
\end{tabular}

\section{References}

Akerlof, George. 1980. A theory of social custom, of which unemployment may be one consequence. Quarterly Journal of Economics 94, no. 4:749-75. Andreoni, James, and B. Douglas Bernheim. 2009. Social image and the 5050 norm: A theoretical and experimental analysis of audience effects. Econometrica 77, no. 5:1607-36.

Andreoni, James, and Ragan Petrie. 2004. Public goods experiments without confidentiality: A glimpse into fund-raising. Journal of Public Economics 88, nos. 7-8:1605-23.

Angrist, Joshua, and Jörn-Steffen Pischke. 2009a. Mostly harmless econometrics. Princeton, NJ: Princeton University Press. 
. 2009b. A note on just identified IV with weak instruments. Unpublished manuscript, London School of Economics, London.

Ariely, Dan, Anat Bracha, and Stephan Meier. 2009. Doing good or doing well? Image motivation and monetary incentives in behaving prosocially. American Economic Review 99, no. 1:544-55.

Bach, Laurent, and Nicolas Serrano-Velarde. 2015. CEO identity and labor contracts: Evidence from CEO transitions. Journal of Corporate Finance 33:227-42.

Baron, David. 2011. Credence attributes, voluntary organizations, and social pressure. Journal of Public Economics 95, nos. 11-12:1331-38.

Benabou, Roland, and Jean Tirole. 2010. Individual and corporate social responsibility. Economica 77, no. 305:1-19.

Bertrand, Marianne, and Sendhil Mullainathan. 2003. Enjoying the quiet life? Corporate governance and managerial preferences. Journal of Political Economy 111, no. 5:1043-75.

Bottazzi, Laura, and Giovanni Peri. 2003. Innovation and spillovers in regions: Evidence from European patent data. European Economic Review 47, no. 4:687-710.

Briant, Anthony, Pierre-Philippe Combes, and Miren Lafourcade. 2010. Dots to boxes: Do the size and shape of geographical units jeopardize economic geography estimations? Journal of Urban Economics 67, no. 3: 287-302.

Cahuc, Pierre, and André Zylberberg. 2004. Labor Economics. Cambridge, MA: MIT Press.

2008. Optimum taxation and layoff taxes. Journal of Public Economics 92, nos. 10-11:2003-19.

Card, David, Kevin F. Hallock, and Enrico Moretti. 2010. The geography of giving: The effect of corporate headquarters on local charities. Journal of Public Economics 94, nos. 3-4:222-34.

Combes, Pierre-Philippe, Gilles Duranton, Laurent Gobillon, and Sébastien Roux. 2010. Estimating agglomeration economies with history, geology, and worker effects. In Agglomeration economics, ed. Edward L. Glaeser. Cambridge, MA: National Bureau of Economic Research.

Combes, Pierre-Philippe, Thierry Mayer, and Jean-François Thisse. 2008. Economic geography. Princeton, NJ: Princeton University Press.

Cronqvist, Henrik, Fredrik Heyman, Mattias Nilsson, Helena Svaleryd, and Jonas Vlachos. 2009. Do entrenched managers pay their workers more? Journal of Finance 64, no. 1:309-39.

D’Aurizio Leandro, and Livio Romano. 2013. Family firms and the Great Recession: Out of sight, out of mind? Working Paper, no. 905, Bank of Italy, Rome.

Davis, Steven, Jason Faberman, and John Haltiwanger. 2006. The flow approach to labor markets: New data sources and micro-macro links. Journal of Economic Perspectives 20, no. 3:3-26. 
Della Vigna, Stefano, John List, and Ulrike Malmendier. 2012. Testing for altruism and social pressure in charitable giving. Quarterly Journal of Economics 127, no. 1:1-55.

De Paola, Maria, Vincenzo Scoppa, and Valeria Pupo. 2014. Absenteeism in the Italian public sector: The effects of changes in sick leave policy. Journal of Labor Economics 32, no. 2:337-60.

Filiz-Ozbay, Emel, and Erkut Ozbay. 2014. Effect of an audience in public goods provision. Experimental Economics 17, no. 2:200-214.

Fontvieille, Louis. 1982. Evolution et croissance de l'administration départementale française, 1815-1974. Economie et Sociétés, Série AF, no. 14: 149-73.

Freeman, Richard. 1997. Working for nothing: The supply of volunteer labor. Journal of Labor Economics 15, no. 1:S140-S166.

Frey, Bruno S., Felix Oberholzer-Gee, and Reiner Eichenberger. 1996. The old lady visits your backyard: A tale of morals. Journal of Political Economy 104, no. 6:1297-1313.

Garicano, Luis, Ignacio Palacios-Huerta, and Candice Prendergast. 2005. Favoritism under social pressure. Review of Economics and Statistics 87 , no. 2:208-16.

Giroud, Xavier. 2013. Proximity and investment: Evidence from plant-level data. Quarterly Journal of Economics 128, no. 2:861-915.

Giroud, Xavier, and Holger Mueller. 2010. Does corporate governance matter in competitive industries? Journal of Financial Economics 95, no. 3:312-31.

2015. Capital and labor reallocation within firms. Journal of Finance 70, no. 4: 1767-1804.

Haltiwanger, John, Ron Jarmin, and Javier Miranda. 2013. Who creates jobs? Small versus large versus young. Review of Economics and Statistics 95, no. 2:347-61.

Harris, Chauncy D. 1954. The market as a factor in the localization of industry in the United States. Annals of the Association of American Geographers 44 , no. 4:315-48.

Ioannides, Yannis, and Henry G. Overman. 2004. Spatial evolution of the US urban system. Journal of Economic Geography 4, no. 2:131-56.

Jung, Philip, and Keith Kuester. 2015. Optimal labor-market policy in recessions. American Economic Journal: Macroeconomics 7, no. 2:124-56.

Kalnins, Arturs, and Francine Lafontaine. 2013. Too far away? The effect of distance to headquarters on business establishment performance. American Economic Journal: Microeconomics 5, no. 3:157-79.

Landier, Augustin, Vinay Nair, and Julie Wulf. 2009. Trade-offs in staying close: Corporate decision making and geographic dispersion. Review of Financial Studies 22, no. 3:1119-48. 
Luo, Xueming, and C. B. Bhattacharya. 2006. Corporate social responsibility, customer satisfaction, and market value. Journal of Marketing 70, no. 4:1-18.

Minni, Claude. 2013. Les ruptures conventionnelles de 2008 à 2012. DARES Analyses, no. 031, Ministère du Travail, de l'Emploi, de la Formation Professionnelle et du Dialogue Socialis, Paris.

Neumark, David, Junfu Zhang, and Stephen Ciccarella. 2008. The effects of Wal-Mart on local labor markets. Journal of Urban Economics 63, no. 2: 405-30.

Nunn, Nathan, and Diego Puga. 2012. Ruggedness: The blessing of bad geography in Africa. Review of Economics and Statistics 94, no. 1:20-36.

Schmitz, Jan, and Jan Schrader. 2015. Corporate social responsibility: A microeconomic review of the literature. Journal of Economic Surveys 29, no. 1:27-45.

Soetevent, Adriaan. 2011. Payment choice, image motivation and contributions to charity: Evidence from a field experiment. American Economic Journal: Economic Policy 3, no. 1:180-205.

Yonker, Scott E. 2013. Do local managers give labor an edge? Research Paper no. 13-16, Center for Economic Studies, US Census Bureau, Washington, DC.

-2017. Geography and the market for CEOs. Management Science (forthcoming). 